Elsevier Editorial System(tm) for European Polymer Journal

Manuscript Draft

Manuscript Number: EUROPOL-D-08-01110R1

Title: Rheological Properties of Asphalt/SBS/Clay Blends

Article Type: Research Paper

Section/Category:

Keywords: Polymer modified asphalt; Clay; SBS; Rheology

Corresponding Author: Dr Giovanni Polacco, PhD

Corresponding Author's Institution: University of Pisa

First Author: Giovanni Polacco, PhD

Order of Authors: Giovanni Polacco, PhD; Pavel Kříž; Sara Filippi, PhD; Jiri Stastna, Professor; Dario Biondi, PhD; Ludovit Zanzotto, Professor

Manuscript Region of Origin:

Abstract: The effect of the addition of clay as a third component in polymer modified asphalts has been investigated. After a preliminary investigation on the binary asphalt/clay and polymer/clay blends, the tertiary blends were prepared by adding the clay and polymer to the asphalt, either separately or in the form of a premixed master batch. Intercalated nanocomposites with comparable interlayer distances and glass transition temperatures were obtained in both cases. However, the results show that the mixing procedure significantly affected the final rheological properties. The master curves built in the linear viscoelastic range and represented in both the frequency and the temperature domains help to visualize and evaluate such differences.

Suggested Reviewers: 

Dear Professor Vancso,

I'm submitting the new version, revised according to referees' suggestions. I would like to thank you and the referees for helping us in improving the quality of the paper.

Best regards

Giovanni Polacco

Department of Chemical Engineering

University of Pisa

Via Diotisalvi 2 -56126 Pisa, ITALY

phone: +39 0502217820, fax: +390502217866

E-mail: g.polacco@,ing.unipi.it 


\title{
Rheological Properties of Asphalt/SBS/Clay Blends
}

Giovanni Polacco ${ }^{\mathrm{a},{ }^{*}}$, Pavel Kříž ${ }^{\mathrm{b}}$, Sara Filippi ${ }^{\mathrm{a}}$, Jiri Stastna ${ }^{\mathrm{b}}$, Dario Biondi ${ }^{\mathrm{a}}$, and Ludovit Zanzotto ${ }^{\mathrm{b}}$

${ }^{a}$ Dipartimento di Ingegneria Chimica, Università di Pisa, Via Diotisalvi 2, $56126=$ Pisa

${ }^{\mathrm{b}}$ Department of Civil Engineering, University of Calgary, 2500 University Drive NW, Calgary, Alberta, T2N 1N4, CANADA

\begin{abstract}
The effect of the addition of clay as a third component in polymer modified asphalts has been investigated. After a preliminary investigation on the binary asphalt/clay and polymer/clay blends, the tertiary blends were prepared by adding the clay and polymer to the asphalt, either separately or in the form of a premixed master batch. Intercalated nanocomposites with comparable interlayer distances and glass transition temperatures were obtained in both cases. However, the results show that the mixing procedure significantly affected the final rheological properties. The master curves built in the linear viscoelastic range and represented in both the frequency and the temperature domains help to visualize and evaluate such differences.
\end{abstract}

\section{Keywords}

Polymer modified asphalt, Clay, SBS, Rheology

* Corresponding author: Tel: +39 050 2217820; Fax: +39 0502217866

E-mail address: g.polacco@ing.unipi.it 


\section{Introduction}

Asphalts are mixtures of aliphatic, aromatic and naphthenic hydrocarbons. They are widely used to provide waterproofing and protective coating and as binders in road construction. The chemical composition of asphalt cannot be defined exactly; therefore, its components are usually grouped into two categories: asphaltenes and maltenes. The latter can be further subdivided into saturates, aromatics and resins. With respect to the structure, asphalt is modeled as a colloid made of asphaltene micelles covered by a stabilizing phase of polar resins, which form the interface with a continuous oily maltenic medium [1].

During the "in life" service of asphalt binders, there are many types of failures, e.g. rutting, fatigue cracking and thermal cracking, which can reduce the quality and performance of pavements. Polymer modified asphalts (PMAs) are blends of asphalt and one or more polymers, usually added in percentages ranging from 3 to $7 \%$ by weight, and were developed to overcome, or at least delay, such problems. A large variety of polymers have been used to produce PMAs, but only a few are satisfactory from both the performance and the cost points of view [2].

Elastomeric thermoplastic block copolymers, especially poly(styrene- $b$-butadiene- $b$-styrene) (SBS) are the most commonly used polymers. The rigid styrenic domains, interconnected through the flexible chains, constitute the nodes of a physical elastomeric network, the structure of which must be preserved after mixing with asphalt. At the same time, there is the important and restrictive requirement of the compatibility between the polymer and the asphalt in order to avoid phase separation during storage at high temperatures. Among the recent literature on asphalt modification with block copolymers, the papers by Becker et al. [3], Airey [4-6], Chen et al. [7], Elseifi et al. [8], Fawcett and McNelly [9], Wloczysiak et al. [10, 11], Kumar et al. [12], Lu and Redelius [13] should be mentioned.

Polymer nanocomposites (PNC) were invented in 1985 at Toyota Central R\&D Labs, Inc. [13], when they introduced the Nylon-6 (N6)/montmorillonite (MMT) system. PNCs then generated great interest in the academic and industrial communities, thus leading to the production of a great volume of scientific and patent literature [14-17]. Before the term nanocomposites was introduced, they were first called hybrid or molecular composites; and, they basically consists of a blend of one 
or more polymers with layered silicates that have a layer thickness in the order of $1 \mathrm{~nm}$ and a very high aspect ratio.

If the silicates are properly dispersed throughout the polymer matrix, the surface area for polymer/filler interaction is much larger than the one formed in systems with conventional fillers. This can lead to the formation of micro- and macro-composites. While conventional inorganic fillers are usually added in percentages varying between 20 and $40 \%$ by weight, in nanocomposites a typical quantity may be between 2 and 5\%. Therefore, one of the advantages is the light weight, which is economically interesting, while other advantages are enhanced mechanical behaviour, high gas barrier properties and improved thermal properties [14-17].

The simple mixing of a polymer and a silicate does not necessarily produce a nanocomposite. Whether the dispersion at the nanometer level is obtained depends both on the chemical properties of the components and on the mixing procedure. The pristine layered silicates are usually miscible only with hydrophilic polymers and ion-exchange reactions with cationic surfactants are frequently used to increase the hydrophobic character of the silicate. Analogously, the introduction of polar groups in the polymeric part can help to disperse clay in the polymer matrix. The level of polymer/clay interaction, of course, influences the final dispersion; and, depending on the obtained morphology, nanocomposites are usually divided into two different categories: i) intercalated nanocomposites, where the macromolecules may be inserted between silicate layers, thus increasing the interlayer distance, but without destroying the original crystallographic structure; and, ii) exfoliated nanocomposites, where the individual clay layers are separated one from each other and dispersed in the polymer matrix. In many cases, it has been shown that several polymer/clay nanocomposites have a mixed intercalated-exfoliated structure [14-17].

The preparation of nanocomposites can be done by several routes, such as melt compounding, in situ polymerization and solution-intercalation $[18,19]$. In the latter, a three-component system is prepared where the solvent dissolves the polymer and delaminates the clay. This should favour the nanocomposite formation, which takes place in a second step where the solvent is removed from the system, e.g. by evaporation. Among the vast variety of available clays, organophilic montmorillonites are known for their ability of swelling and thixotropic gel formation in organic media [20-22]. This can lead to the formation of stable suspensions [23] and, for high clay content, to a continuous structure that can show a gel-like behaviour. Nevertheless, the solution-intercalation 
is not always applicable; because, in some cases, when the solvent is removed, the clay platelets tend to re-aggregate before a polymer intercalation can be established [24, 25].

For this paper, asphalt/clay/polymer nanocomposites have been prepared, since asphalt can be considered as an intermediate between a solvent and a polymer. Therefore, we have a threecomponent system, where asphalt, due to its polarity and relatively low molecular weight, may play a role similar to the one of a solvent, with the important difference that it is destined to remain as the main part of the blend and is not removed. In this sense, the preparation of the nanocomposite can be done in the conventional way used for asphalt modification, which does not involve new equipment or procedures.

As mentioned above, there is a great volume of literature available on polymer nanocomposites, and almost all kinds of commercial polymers have already been extensively investigated. It is important to note that, with styrenic block copolymers, the clay prevalently interacts with the styrenic component $[26,27]$. Lee et al. showed that an organically modified montmorillonite leads to a change in the microphase separation behaviour of styrene-(ethylene-co-butylene)-styrene triblock copolymers (SEBS), thus also influencing the order-disorder transitions [28]. Analogously, the influence of the addition of small quantities of anisotropic layered silicates on the ordering of block copolymers was studied by Krishnamoorti et al. [29] and Silva et al. [30-32]. The effect of the preparation technique was investigated by Yamaguchi and Yamada [33], Chang et al. [34], Carastan and Demarquette [35].

To our knowledge, only one research group has studied the modification of asphalt with clay/polymer compounds. In particular, conventional asphalts were modified by the addition of i) SBS premixed with a kaolinite [36], ii) SBS premixed with an organobentonite (in this case, a silane coupling agent was also added to the blend) [37], and iii) SEBS premixed with a kaolinite [38]. In all cases, several polymer/clay ratios were used; and, the obtained PMAs have been characterized by storage stability, blend morphology and, to a minor extent, mechanical and rheological properties. The main finding of this series of studies is that the addition of the clay may have a very positive impact on storage stability, where the stabilizing effect was considered to be due to a variation of the density of the polymer-rich phase, which was induced by the presence of the clay. However, the storage stabilization is obtained only if polymer and clay are premixed and not if they are added separately to the asphalt. This means that, during the preliminary mixing of polymer and clay, the two components interact and bond one to each other in a way that is at least 
partially maintained after the asphalt modification. Nevertheless, the authors refer to the threecomponent system as a blend or a compound and do not investigate if there is a nanocomposite nature to the system.

In this work, asphalt modified with SBS and an organically modified montmorillonite (Cloisite 20A) were also prepared by melt mixing using two different procedures. In the first one, the clay was premixed with the polymer to form an intercalated nanocomposite, which was then used as the asphalt modifier. In the second one, polymer and clay were added to the asphalt as separate components. The blends were then characterized by X-ray scattering and modulated differential scanning calorimetry. Moreover, their rheological properties were evaluated and compared with those of a "classic" PMA obtained by the addition of SBS alone.

\section{Materials and Methods}

Conventional asphalt (BA) from vacuum distillation, with 170/220 Pen grade, ring and ball softening point $(\mathrm{RB})=43^{\circ} \mathrm{C}$ and penetration $=190 \mathrm{dmm}$, was used as a base. The polymer modifier was SBS Kraton ${ }^{\circledR D} 1102$ (styrene content $=29.5 \%$ by weight, melt index $=6 \mathrm{~g} / 10 \mathrm{~min}\left(200^{\circ} \mathrm{C}, 5\right.$ $\mathrm{Kg}$ ), hardness $=70$ in Shore A scale); and, the clay was Cloisite 20A, an organoclay (subsequently referred to as 20A) from Southern Clay Products Inc. 20A was prepared from a sodium montmorillonite having a cation exchange capacity of $0.926 \mathrm{meq} \cdot \mathrm{g}^{-1}$ by treatment with $0.95 \mathrm{meq} \cdot \mathrm{g}^{-1}$ of $\mathrm{Me}_{2}(\mathrm{HT})_{2} \mathrm{NCl}$ (dimethyldihydrogenated-tallow ammonium chloride). Hydrogenated tallow is a blend of saturated $n$-alkyl groups with an approximate composition of $\mathrm{C}_{18}$ at $65 \%, \mathrm{C}_{16}$ at $30 \%$ and $\mathrm{C}_{14}$ at $5 \%$. The organic content of $20 \mathrm{~A}$ was $38.5 \mathrm{wt} \%$ as determined by thermogravimetric analysis (TGA). The polymer was carefully dried under vacuum at $70^{\circ} \mathrm{C}$, while both the asphalt and the organoclay were used as received from the suppliers.

Three sets of blends were prepared: 1) SBS/20A, 2) BA/20A and 3) BA/SBS/20A. The SBS/20A blends were prepared by melt compounding in a Brabender Plasticorder static mixer of $50 \mathrm{~mL}$ capacity, preheated to $190^{\circ} \mathrm{C}$. The rotor speed was maintained at $30 \mathrm{rpm}$ for about 2.5 minutes and then it was increased gradually (in 30 seconds increments) to $60 \mathrm{rpm}$. The organoclay was added into the molten polymer matrix before increasing the rotor speed. The overall blending time was 13 minutes. The applied torque and blend temperature were recorded during the whole compounding period. At the end, the molten products were extracted from the mixer and cooled naturally in the 
atmosphere. Blank samples, which were to be employed as references, were prepared from pure polymers with the same procedure.

With regard to asphalt modification, the typical mixing procedure was as follows: aluminium cans of approximately $500 \mathrm{~mL}$ were filled with 250-260 grams of asphalt and put in a thermoelectric heater. When the asphalt temperature reached $180^{\circ} \mathrm{C}$, a high shear mixer was dipped into the can and set to about 4,000 rpm. The polymer and clay (or the polymer/clay nanocomposite) were added gradually (5 grams per minute), while keeping the temperature within the range of $180 \pm 1{ }^{\circ} \mathrm{C}$ during the addition and the subsequent 1.0 hour of mixing. Finally, the obtained PMA was split into appropriate amounts to prepare samples for the characterization. The samples were stored in a freezer at $-20^{\circ} \mathrm{C}$.

After preparation, the PMAs were characterized by the classical ring and ball softening point procedure (ASTM D36-76), the storage stability test (UNI EN 13399) and fluorescence microscopy (UNI prEN 13632). The stability test consists of keeping the PMA in a test tube stored in a vertical position at $180^{\circ} \mathrm{C}$ for $72 \pm 1$ hours and then taking samples from the top and bottom parts. For the morphological analysis, asphalt samples were taken directly from the mixing can during the PMA preparation and poured into small cylindrical moulds $(1 \mathrm{~cm}$ diameter, $2 \mathrm{~cm}$ height). In order to preserve the instantaneous morphology, the moulds were preheated to the mixing temperature, so that the asphalt was not subjected to quenching when in contact with the metal. When filled, the moulds were put into an oven at $180^{\circ} \mathrm{C}$ for 15 minutes, cooled to room temperature and then chilled to $-30^{\circ} \mathrm{C}$. The cold samples were then fractured, and the fracture surfaces were examined with a LEICA DM LB fluorescence microscope.

Wide angle X-ray diffraction (WAXD) measurements were made in reflection mode with a Siemens D500 Krystalloflex 810 apparatus X-ray, with a wavelength of $0.1542 \mathrm{~nm}$ at a scan rate of $2.0^{\circ} \cdot \mathrm{min}-1$. The clay was analyzed as a powder; and, the SBS/20A composites were analyzed as disks of $2 \mathrm{~mm}$ thickness and $20 \mathrm{~mm}$ diameter prepared by compression moulding of the meltcompounded materials. The $\mathrm{BA} / 20 \mathrm{~A}$ and $\mathrm{BA} / \mathrm{SBS} / 20 \mathrm{~A}$ samples were obtained directly from the mixing can and poured into small cylindrical moulds (10 $\mathrm{mm}$ diameter, $1 \mathrm{~mm}$ height), externally shaped to be directly allocated in the measurement instrument.

Calorimetric analysis was performed by a Q100 differential scanning calorimeter (TA Instruments) equipped with the modulated temperature setup and liquid nitrogen cooling system. Ultra pure 
helium $(99.999 \%)$ was used to purge $(50 \mathrm{~mL} / \mathrm{min})$ the cell. Standard aluminum sealed pans were used for all experiments. The sample mass was in the range of 7-10 $\mathrm{mg}$. The experimental setup for asphalts was as follows: fast heat up to $150^{\circ} \mathrm{C}$, isotherm for 5 minutes, slow cooling to $-100^{\circ} \mathrm{C}$ (rate of $10^{\circ} \mathrm{C} / \mathrm{min}$ ), isotherm at $-100^{\circ} \mathrm{C}$ for 10 minutes, and the sample is ready for the modulated differential scanning calorimetry (MDSC). MDSC parameters during the run: linear heating rate at $2-4^{\circ} \mathrm{C} / \mathrm{min}$, amplitude of $1-2^{\circ} \mathrm{C}$, and period of $40-60$ seconds were found to be optimal for the investigation of asphalts. Standard differential scanning calorimetry (DSC) was performed at: $4^{\circ} \mathrm{C} / \mathrm{min}$ for asphalts, and $10^{\circ} \mathrm{C} / \mathrm{min}$ for SBS and organoclay.

Dynamic oscillatory measurements were performed in isothermal conditions by using a TA ARES A-33A rheometer, which operates under strain control. The geometries were the cone and plate (25 and $50 \mathrm{~mm}$ diameters, cones of 0.01 and $0.04 \mathrm{rad}$, respectively) and torsion bar (with linear dimensions of $37 * 12.5 * 2.7$ ), which was used at low temperatures. The frequency was varied from 0.01 to $1.00 \mathrm{~Hz}$ at low temperatures and from 0.05 to $5.00 \mathrm{~Hz}$ at medium and high temperatures.

The reason why different geometries were used is the wide range of temperatures covered, thus changing the consistency of the sample from that of a soft viscoelastic solid (when a plate-plate can be used) to a brittle glassy material (when the torsion bar is necessary). The advantages and problems associated with such testing are fully discussed in a previous paper [39].

Asphalt samples were prepared by pouring the molten material into rubberized moulds of appropriate dimensions and stored in a freezer. This procedure assures that the morphology formed during the mixing stage is preserved until the rheological measurement is carried out, even for the PMAs that were shown to be rather unstable. Preliminary strain sweep tests were performed in order to ensure that all experimental conditions remained in the linear domain. The test temperature was varied from -40 to $90^{\circ} \mathrm{C}$, in order to construct the master curves of the dynamic material functions by using the time-temperature superposition principle [40, 41].

\section{Results and Discussion}

As noted in the previous section, two sets of binary blends were first prepared and characterized by $\mathrm{X}$-ray analysis, in order to find out if, and what type of, nanocomposites were formed when blending BA and SBS separately with the clay. With regard to the BA/20A blends, four different compositions were prepared, as reported in Table 1 together with the softening point (at the end of mixing and after the storage stability test) and penetration. The effect of clay content on the softening point and penetration was not linear: the variation of softening point was very small for 
the lower clay loads and became important only for the B3 and B4 compositions, while the penetration was reduced to about one half of the initial value in the B1 and B2 compositions and further halved for B3 and B4. This is a first indication that no exfoliation took place, because the behaviour corresponded to what was expected when conventional fillers are added in similar concentrations. At low clay loads, the particles remained separate one from each other; and, at high temperatures, the soft asphalt matrix flowed as it would do without the clay. The situation changed at higher clay loads, where the clay particles may not have been completely dispersed in the asphalt and, therefore, interacted with each other, forming a continuum that strongly affected the overall rheological properties. The storage test confirms that asphalt and clay were somehow bonded so that no phase separations occurred, even if the two materials had specific densities quite different one from each other $\left(1,015\right.$ and $1,770 \mathrm{Kg} / \mathrm{m}^{3}$ for asphalt and clay respectively).

In Figure 1, the X-ray diffraction (XRD) patterns of asphalt, clay, and some of the blends are reported. The asphalt had a halo, which is typical of amorphous materials, while the clay had a main peak at $2 \theta=3.5^{\circ}$, which corresponds to an interlayer spacing, $\mathrm{d}_{001}$, of $2.5 \mathrm{~nm}$. When the asphalt was mixed with the clay, irrespective of the clay load, the interlayer spacing results shifted to a lower angle $\left(2 \theta=2.0^{\circ}\right.$, corresponding to $\left.\mathrm{d}_{001}=4.4 \mathrm{~nm}\right)$, thus indicating that the asphalt was able to intercalate the organoclay and was also probably able to exfoliate part of the stacks. However, none of the reported curves indicates a complete exfoliation of the clay in the asphalt matrix.

The SBS/20A binary blends were prepared with clay loads equal to 5, 10 and $40 \mathrm{wt} \%$ of clay (Figure 2). The polymer had a spectrum that reflected its amorphous character, while a shift of the main peak of the clay toward lower angles was observed. In all blends, intercalated nanocomposites characterized by a $\mathrm{d}_{001}$ spacing of about $3.6 \mathrm{~nm}$ were obtained, irrespective of the clay loading. Therefore, it was found that: i) in both binary blends (BA/20A and SBS/20A), there was intercalation with interlayer spacing not affected by the clay concentration (at least in the investigated range of compositions); and, ii) the $\mathrm{d}_{001}$ values indicate that the asphalt had greater compatibility with the clay than with the polymer.

Finally, a conventional blend of BA/SBS $=96 / 4(\mathrm{w} / \mathrm{w})$ and two tertiary mixes of BA/20A/SBS = 93.33/4/2.67 (w/w/w) were prepared. The first tertiary blend corresponds to a physical mix (PM) prepared by adding the polymer and clay separately to the asphalt, while the second tertiary blend was obtained by adding the SBS/clay (60/40) nanocomposite as a master batch (MB). The XRD patterns (Figure 3 ) indicate that, in both cases, the mixes resulted in intercalation with an interlayer 
spacing equal to $4.4 \mathrm{~nm}$. The distance between the layers was equal to that obtained by mixing asphalt and clay without the polymer; and, this value did not seem to be affected by the mixing sequence. This suggests that asphalt determined the interlayer distance, independent of the polymer presence; and, one can suppose that the asphalt particles were substituted for the polymer macromolecules pre-intercalated during the master batch formation. However, it will be shown that the $\mathrm{PM}$ and $\mathrm{MB}$ blends are not equivalent from the rheological point of view.

With regard to the MDSC characterization, the first aspect investigated was that of glass transition temperatures, which may give a good indication of the interactions occurring between the components. For polymers, the reversing signal can be used to describe the changes in glass transition. In particular, the derivative of reversing heat capacity versus temperature is very useful in the determination of the compatibility of the amorphous phase. The signal itself represents the rate at which the molecules are passing through the glass transition. If the amorphous phase is fully compatible and uniform, the shape of the signal should correspond to a Gaussian distribution with a single maximum. For incompatible blends, however, multiple peaks are observed, suggesting that there are two or more separate amorphous domains, each of which passes through its own glass transition with maxima at different temperatures [42-44]. The obtained results are presented in Figure 4.

The major difference among the samples was associated with the presence of SBS. The samples containing SBS, i.e. BA/SBS, PM and MB, showed slightly higher molecular mobility at very low temperatures (at around $-50^{\circ} \mathrm{C}$ ). The butadiene units in SBS already pass through the glass transition at about $-95^{\circ} \mathrm{C}$ during heating, thus increasing the overall molecular mobility. The glass transition was also symmetrically broadened in samples containing SBS, which is due to high molecular weight of the added polymer. Generally, the broader the molecular weight distribution, the broader the glass transition [45].

It is also interesting to observe that SBS affected the crystallinity of the asphalt. With respect to samples not containing SBS, the melting enthalpy of samples containing SBS was lower by 1-1.5 $\mathrm{J} / \mathrm{g}$ or by $3-5 \mathrm{~J} / \mathrm{g}$, if the data are obtained by MDSC or by DSC, respectively. This difference between MDSC and DSC is not surprising, because MDSC is generally not quantitative if the melting is partly reversing[46], as is the case for asphalts. Lower crystallinity suggests improved low-temperature properties of the binder, because crystals are very rigid and are also known to restrict the molecular motion of amorphous molecules at low temperatures (increase amount of 
glassy phase at the particular temperature within the transition range) [47]. According to the results, neither the addition of organoclay nor the order of the addition seemed to significantly affect the glass transition and melting. The nano-particles, if their size is less than $100 \mathrm{~nm}$, are known to have an impact on the glass transition of amorphous polymers [48]. No effect of clay on glass transition was observed in studied blends. This may indicate that the particles were either larger or not well dispersed. Results of the standard DSC experiments (Figure 5) showed that crystallization was mainly affected by the presence of SBS. In particular, the onset of crystallization was more rapid in samples without SBS (BA, B1); and, the total melting/crystallization enthalpy was lower in samples containing SBS (BA/SBS, PM, MB). Again, no significant effects due to the presence of organoclay or the order of addition were observed.

When studying the samples of asphalt by small amplitude sinusoidal oscillations, the results are usually portrayed via the master curves of dynamic material functions (storage modulus, G'; loss modulus, G”; and loss tangent, $\tan \delta$ ) [39, 49]. In fact this was possible because all the analyzed materials showed to be thermo-rheologically simple thus making possible to apply the timetemperature superposition principle. With regard to the sample geometries, for BA, B1 and BA/SBS, $25 \mathrm{~mm}$ diameter parallel plates were used at $\mathrm{T}>20^{\circ} \mathrm{C}, 10 \mathrm{~mm}$ parallel plates at $\mathrm{T}=10-30$ ${ }^{\circ} \mathrm{C}$ and rectangular torsional bars $(25.5 \times 12 \times 2.65 \mathrm{~mm})$ at $\mathrm{T}$ lower than $20{ }^{\circ} \mathrm{C}$. For $\mathrm{MB}$ and $\mathrm{PM}$ samples the $25 \mathrm{~mm}$ diameter parallel plates were used at $\mathrm{T}>30^{\circ} \mathrm{C}$ ), $10 \mathrm{~mm}$ parallel plates at $\mathrm{T}=10$ $30{ }^{\circ} \mathrm{C}, 50 \mathrm{~mm}$ parallel plates at $\mathrm{T}>100^{\circ} \mathrm{C}$ and rectangular torsional bars $(25.5 \times 12 \times 2.65 \mathrm{~mm})$ at $\mathrm{T}<20$ ${ }^{\circ} \mathrm{C}$. From the linear viscoelastic functions, only the loss modulus and the loss tangent may show some structural transitions in the asphalt sample. The strongest transition is the $\alpha$-transition from the rubbery state to the glassy state; and, it is identified by the maximum of the loss modulus, $G$ ' $(\omega)$, in the $\omega$ - frequency domain. The loss tangent usually does not reveal any transitions in the samples of conventional (unmodified) asphalt. When the asphalt is modified by SBS copolymer, one can find a local maximum on the graph of loss tangent. The position of this maximum is characteristic for the studied asphalt/SBS copolymer system.

Asphalt is a material with very high temperature susceptibility and at a sufficiently high temperature, it starts to flow as a Newtonian fluid. The beginning of this flow can be seen on the graph of the steady shear viscosity [50]. When the master curves of dynamic material functions are available, one can estimate the beginning of the Newtonian flow from the plot of the loss compliance, $J^{\prime}(\omega)$. The Newtonian flow (characterized by the constant zero-shear viscosity, $\eta_{0}$ ) is represented by the explicit asymptotic term, $1 / \omega \eta_{0}$, in the loss compliance function [40, 41]. Thus, 
by finding the asymptote of $S^{\prime}(\omega)$, at low frequencies one can estimate $\eta_{0}$ and construct the modified loss compliance function:

$J^{\prime}{ }_{c}(\omega)=J^{\prime}(\omega)-1 / \omega \eta_{0}$

The plot of $J^{\prime}{ }_{c}(\omega)$ has a characteristic total maximum (similarly as $G$ " does), above which the Newtonian flow behaviour begins. The elimination of the Newtonian flow from J" allows the construction of a modified loss tangent function:

$\tan _{c} \delta(\omega)=J_{c}{ }_{c}(\omega) / J^{\prime}(\omega)$

This linear viscoelastic function represents the ratio of mechanical energy dissipated (Newtonian flow eliminated) to the mechanical energy stored by the material in one cycle. The modified loss tangent has also a strong maximum; thus, by combining the three functions of $G{ }^{\prime},{ }^{\prime}{ }_{\mathrm{c}}$ and $\tan _{\mathrm{c}} \delta$, one can obtain a complete picture of possible transitions in the studied sample.

The basic assumption of the outlined method is that the tested material is rheologically simple [40, 41]. Only if this is the case can one construct the master curves of dynamic material functions, with the help of the time-temperature superposition principle [40, 41]. During the process of such construction, the horizontal shifting factors $\mathrm{a}_{\mathrm{T}}$ are obtained. In asphalt samples, $\mathrm{a}_{\mathrm{T}}$ is quite often described by the Williams-Landel-Ferry (WLF) form [40, 41]:

$\log \mathrm{a}_{T}=\frac{-c_{1}\left(\mathrm{~T}-\mathrm{T}_{\mathrm{r}}\right)}{\left(\mathrm{c}_{2}+\mathrm{T}-\mathrm{T}_{\mathrm{r}}\right)}$

where $\mathrm{T}$ is the temperature, $\mathrm{T}_{\mathrm{r}}$ is the reference temperature, and $\mathrm{c}_{1}$ and $\mathrm{c}_{2}$ are constants.

Since the independent variable of dynamic master functions $\left(G^{\prime}, G^{\prime \prime}, J^{\prime}, J^{\prime \prime}\right.$, etc) is $\omega=\varpi \mathrm{a}_{\mathrm{T}}$, where $\varpi$ is the frequency of the dynamic test at a constant temperature, one can transform the frequency domain to the temperature domain. Thus, for the fixed test frequency, $\omega_{0}$, and the WLF form of $\mathrm{a}_{\mathrm{T}}$, one obtains the following transformation:

$\mathrm{T}=\mathrm{T}_{\mathrm{F}}+\frac{\mathrm{c}_{2}\left[\log \left(\omega_{0}\right)-\log (\omega)\right]}{\left[\mathrm{c}_{1}-\log \left(\omega_{0}\right)+\log (\omega)\right]}$ 
With the help of equation (4) and with all the basic assumptions satisfied, the dynamic experiments can be transformed to the experiment in which the sample is probed by the harmonic input with a fixed frequency $\left(\omega_{0}\right)$ and a varying temperature with a very small rate of change. The results of this procedure can then be compared with the DSC testing of the studied sample.

The outlined program was followed; and, finally, the functions were normalized by their maxima (at appropriate domains) for samples BA, BA/SBS, B1, PM and MB. From the graphs of $\tan \delta$ in Figures 6 and 7, one can see that samples BA and B1 behaved quite similarly in the frequency domain. The exception was the behaviour of BA at highest frequencies, where the loss tangent attained a constant asymptotic value, but was still decreasing for sample B1. Sample BA/SBS showed a characteristic local maximum of $\tan \delta$ before the Newtonian increase of $\tan \delta$ begins. The loss tangent of samples PM and MB looked quite different from each other: PM appeared to be qualitatively similar to BA/SBS, with a local maximum preceding the continuous increase of $\tan \delta$, but shifted to the lower frequencies; and, MB showed a behaviour similar to BA and B1, where the maximum in $\tan \delta$ was not visible, but somehow hidden by the interactions between the polymer and the clay.

After the transformation of the frequency domain to the temperature domain (with the testing frequency $\omega_{0}=0.01 \mathrm{~Hz}$ ), one can see that samples BA and B1 again exhibited very similar behaviour (BA is reported in Figure 8). Moreover, at the chosen frequency[51] the estimated glass transition temperatures (the position of maximum of $G^{\prime \prime}\left(\mathrm{T}, \omega_{0}\right)$ ), in both cases, were in agreement with the DSC values (Table 2). Sample BA/SBS displayed typical behaviour of asphalt modified with SBS copolymer. In this case, the glass transition temperature was again close to that estimated in the DSC experiment; and, the Newtonian transition temperature, $\mathrm{T}_{\mathrm{N}}=72.7^{\circ} \mathrm{C}$, was not too different from $\mathrm{T}_{\mathrm{N}}$ obtained for $\mathrm{BA}-70.3^{\circ} \mathrm{C}$.

On the other hand, the shape of $\tan _{c} \delta$ (for BA/SBS) was different from the shape of $\tan _{c} \delta$ in BA or B1, with a much "sharper" peak in BA/SBS, as shown in Figure 9. There was a relatively fast decrease of $\tan _{c} \delta$ from $\mathrm{T}=36.0{ }^{\circ} \mathrm{C}$ (the position of the maximum of $\tan _{\mathrm{c}} \delta$ in BA/SBS) to the suggestion of a first shoulder before $\mathrm{T}=60^{\circ} \mathrm{C}$ and another "weak" shoulder before about $70^{\circ} \mathrm{C}$. The Newtonian state was reached around $80^{\circ} \mathrm{C}$.

Sample MB, shown in Figure 10, had a maximum of $G^{\prime \prime}\left(\mathrm{T}, \omega_{0}\right)$ at $\mathrm{T}=-35.2^{\circ} \mathrm{C}$, which was basically equal to the value obtained in the DSC experiment, and the Newtonian transition at $\mathrm{T}=70.3^{\circ} \mathrm{C}$, 
which is close to that of BA/SBS $\left(72.7^{\circ} \mathrm{C}\right)$ and identical to that in BA. On the other hand, the shape of $\tan _{\mathrm{c}} \delta$ was very different from that of BA/SBS; and, there was a suggestion of a shoulder at $\mathrm{T} \sim$ $20^{\circ} \mathrm{C}$ and a steep descent of $\tan _{\mathrm{c}} \delta$ after the maximum at $\mathrm{T}=58.4{ }^{\circ} \mathrm{C}$. The Newtonian state was attained before $\mathrm{T} \sim 80^{\circ} \mathrm{C}$. At low temperatures, $\tan _{\mathrm{c}} \delta$ of sample $\mathrm{MB}$ seemed to go to a constant asymptotic value or decreased very slowly. The glass transition peak $\left(G^{\prime \prime}\left(\mathrm{T}, \omega_{0}\right)\right)$ was very broad and the narrow Newtonian transition peak $\left(\mathrm{J}{ }_{\mathrm{c}}\left(\mathrm{T}, \omega_{0}\right)\right)$ resembled that of sample BA.

The $\left(\mathrm{T}-\omega_{0}\right)$ map of sample PM, shown in Figure 11, was very different. Again, there was agreement between the glass transition from the DSC experiment and the rheology, with a value of $\mathrm{T}_{\mathrm{g}}$ that was almost the same as that of sample MB. One significant difference from the other samples was that the Newtonian transition was at $\mathrm{T}_{\mathrm{N}}=90.6{ }^{\circ} \mathrm{C}$, and the maximum of $\tan _{\mathrm{c}} \delta$ was reached at $\mathrm{T}=83.4{ }^{\circ} \mathrm{C}$; and, the Newtonian state was, therefore, reached at $\mathrm{T} \sim 100{ }^{\circ} \mathrm{C}$. However, the most striking difference from the other samples was the shape of $\tan _{\mathrm{c}} \delta$ that, in sample PM, had a relatively strong local maximum at about $\mathrm{T}=30^{\circ} \mathrm{C}$, with the peak of the absolute maximum of $\tan _{\mathrm{c}} \delta$ much sharper than in the other samples. Therefore, the overall shape of $\tan _{\mathrm{c}} \delta$ points to a very different material behaviour at $\mathrm{T}>-20^{\circ} \mathrm{C}$ : the elasticity of $\mathrm{MB}$ was much higher, and the dissipation of mechanical energy was much lower than in the other samples.

\section{Conclusions}

The effect clay addition as a third component in polymer modified asphalts was investigated in a system composed of a soft base asphalt and a radial SBS block copolymer. As a first step, binary blends were prepared with the asphalt and clay, in order to evaluate their degree of interaction. It was found that asphalt and clay gave intercalated nanocomposites, in which a partial degree of exfoliation was also probably present. Tertiary blends were then prepared either by the separate additions of clay and polymer to the asphalt or by addition of a premixed polymer/clay intercalated nanocomposites.

In all cases, the X-ray analysis showed an intercalation between the clay stacks with an interlayer distance that seemed not to be affected by the mixing procedure. Analogously, the mixing procedure did not significantly affect the low-temperature glass transitions as measured by differential scanning calorimetry. 
On the other hand, some important differences appeared when studying the rheological properties of the blends. The master curves obtained in the classic dynamic tests performed in the linear viscoelastic range showed that the physical mix had rheological behaviour that qualitatively resembled that of a conventional SBS modified asphalt, while a behaviour similar to that of a clay/asphalt mix was obtained from premixing. This confirms that the order of addition of the components had a significant effect on the internal structure of the blends and, therefore, on its rheological behaviour. As is quite common in polymer modified asphalts, the main differences appeared at low frequencies or high temperatures, which can be seen, for example, from the onset of the Newtonian behaviour.

Generally, the elasticity of the blend prepared by using a master batch was much higher and the dissipation of mechanical energy much lower than in the case of a physical mix. Considering the polymer and asphalt separately, the latter showed a higher compatibility with the clay. Therefore, a physical mix of the three components should lead to nanocomposites, in which the intercalation in the clay layers is mainly due to asphalt molecules, while the asphalt/polymer interactions are almost not affected by the presence of the clay. A different morphology was probably obtained when the polymer was premixed with the clay; because, in this case, the macromolecules were first intercalated between the clay layers, and they are then able to maintain this position, at least partially. In this way, the clay, that was present in a small quantity, with respect to the total asphalt content, remained bonded with the polymer and may have significantly affected the overall properties.

\section{Acknowledgements}

The authors would like to acknowledge the Natural Sciences and Engineering Research Council of Canada and Husky Energy Inc. for their financial support of this work.

\section{References}

1. Read J, Whiteoak D. The Shell Bitumen Handbook, fifth edition. London: Thomas Telford Publishing, 2003. 
2. Polacco G, Stastna J, Biondi D, Zanzotto L. Relation Between Polymer Architecture and Nonlinear Viscoelastic Behavior of Modified Asphalts. Current Opinion in Colloid \& Interface Science 2006; 11(4): 230-245.

3. Becker IM, Muller AJ, Rodriguez Y. Use of rheological compatibility criteria to study SBS modified asphalts. J Appl Polym Sci 2003; 90:1772-1782.

4. Airey GD, Singleton TM, Collop AC. Properties of polymer modified bitumen after rubberbitumen interaction. J Mater Civ Eng 2002; 14:344-354.

5. Airey GD. Rheological properties of styrene butadiene styrene polymer modified road bitumens. Fuel 2003; 82:1709-1719.

6. Airey GD. Styrene butadiene styrene polymer modification of road bitumens. J Mater Sci 2004; 39:951-959.

7. Chen JS, Liao MC, Shiah MS. Asphalt modified by styrene-butadiene-styrene triblock copolymer: morphology and model. J Mater Civ Eng 2002; 143:224-229.

8. Elseifi MA, Flintsch GW, Al-Qadi IL. Quantitative effect of elastomeric modification on binder performance at intermediate and high temperatures. J Mater Civ Eng 2003; 151:3240.

9. Fawcett AH, McNelly T. Blends of bitumens with polymers having a styrene component. Polym Eng Sci 2001; 417:1251-1264.

10. Wloczysiak P, Vidal A, Papirer E, Guvin P. Relationships between rheological properties, morphological characteristics, and composition of bitumen-styrene butadiene styrene copolymers mixes. I. A three-phase system. J Appl Polym Sci 1997; 65:1595-1607.

11. Wloczysiak P, Vidal A, Papirer E. Relationships between rheological properties, morphological characteristics, and composition of bitumen-styrene butadiene styrene copolymers mixes. II. A thermodynamical interpretation. J Appl Polym Sci 1997; 65:16091618 .

12. Kumar P, Chandra S, Bose S. Rheology of the polymer modified bitumen. Highway Research Bulletin 2004; 71:119-135.

13. Lu X, Redelius P. Polymer modified bitumen. Recent Research Developments. Applied Polymer Science 2002; 1:501-528.

14. Paul DR, Robeson LM. Polymer nanotechnology: Nanocomposites. Polymer 2008; 49 : 3187-3204.

15. Ray SS, Okamoto M. Polymer/layered silicate nanocomposites: a review from preparation to processing. Prog Polym Sci 2003; 28: 1539-1641. 
16. Ahmadi SJ, Huang YD, Li W. Synthetic routes, properties and future applications of polymer-layered silicate nanocomposites. J. Mat. Sci. 2004; 39: 1919-1925.

17. Alexandre M, Dubois P. Polymer-layered silicate nanocomposites: preparation, properties and uses of a new class of materials. Mat. Sci. Eng. 2000; 28: 1-63.

18. Okada A, Fukushima A, Kawasumi M, Inagaki S, Usuki A, Sugiyama S, Kurauchi T, Kamigaito O. Composite material and its preparation. 1987; US 4739007.

19. Jordan JW. Organophilic bentonites. I. Swelling in organic liquids. Journal of Physical and Colloid Chemistry 1949; 53:294-306.

20. Lagaly G, Malberg R. Disaggregation of alkylammonium montmorillonites in organic solvents. Colloids and Surfaces 1990; 49(1-2):11-27.

21. Slabaugh WH, Hiltner PA. Swelling of alkylammonium montmorillonites. Journal of Physical Chemistry 1968; 72(12):4295-4298.

22. Moraru VN. Structure formation of alkylammonium montmorillonites in organic media. Applied Clay Science 2001; 19(1-6):11-26.

23. Luckham PF, Rossi S. The colloidal and rheological properties of bentonite suspensions. Advances in Colloid and Interface Science 1999; 82(1-3):43-92.

24. Filippi S, Mameli E, Marazzato C, Magagnini PL. Comparison of solution-blending and melt-intercalation for the preparation of poly(ethylene-co-acrylic acid)/organoclay nanocomposites. Euro Polym Jnl 2007; 43:1645-1659.

25. Filippi S, Marazzato C, Magagnini PL, Famulari A, Arosio P, Meille SV. Structure and morphology of HDPE-g-MA/organoclay nanocomposites: Effects of the preparation procedures. Euro Polym Jnl 2008; 44(4):987-1002.

26. Lai SM, Chen CM. Preparation, structure, and properties of styrene-ethylene-butylenestyrene block copolymer/clay nanocomposites: Part III. Effectiveness of compatibilizers. Euro Polymer Jnl 2007; 43:2254-2264.

27. Hasegawa N, Usuki A. Arranged microdomain structures induced by clay silicate layers in block copolymer-clay nanocomposites. Polymer bulletin 2003; 51:77-83.

28. Lee CH, Kim HB, Lim ST, Seok Kim HS, Kwon YK, Choi HJ. Ordering Behavior of Layered Silicate Nanocomposites with a Cylindrical Triblock Copolymer. Macromol Chem Phys 2006; (207):444-455.

29. Krishnamoorti R, Silva SA, Mitchell CA. Effect of silicate layer anisotropy on cylindrical and spherical microdomain ordering in block copolymer nanocomposites. J Chem Phys $2001 ;(-115): 7175-7181$. 
30. Silva AS, Mitchell C, Tse MF, Wang HC, Krishnamoorti R. Templating of cylindrical and spherical block copolymer microdomains by layered silicates. J Chem Phys 2001; 115:71667174.

31. Ren J, Silva AS, Krishnamoorti R. Linear Viscoelasticity of Disordered PolystyrenePolyisoprene Block Copolymer Based Layered-Silicate Nanocomposites. Macromolecules $2000 ; 33: 3739-3746$.

32. Krishnamoorti R, Ren J, Silva AS. Shear response of layered silicate nanocomposites. J Chem Phys 2001; 114(11):4968-4973.

33. Yamaguchi T, Yamada E. Preparation and mechanical properties of clay/polystyrene-blockpolybutadieneblock-polystyrene triblock copolymer (SBS) intercalated nanocomposites using organoclay containing stearic acid. Polym Int 2006; 55:662-667.

34. Chang YW, Shin JY, Ryu SH. Preparation and properties of styrene-ethylene/butylenestyrene (SEBS)-clay hybrids. Polym Int 2004; 53:1047-1051.

35. Carastan DJ, Demarquette NR. Microstructure of Nanocomposites of Styrenic Polymers. Macromol Symp 2006; 233:152-160.

36. Ouyang C, Wang S, Zhang Y, Zhang Y. Preparation and properties of styrene-butadienestyrene copolymer/kaolinite clay compound and asphalt modified with the compound. Polymer Degradation and Stability 2005; 87:309-317.

37. Wang YP, Liu DJ, Wang YP, Gao JM. Preparation and properties of asphalt modified with SBS/organobentonite blends. Polymers \& Polymer composites 2006; 14(4):403-411.

38. Ouyang C, Wang S, Zhang Y, Zhang Y. Thermo-rheological properties and storage stability of SEBS/kaolinite clay compound modified asphalts. Euro Polym Jnl 2006; 42: 446-457.

39. Polacco G, Vacin OJ, Biondi D, Stastna J, Zanzotto L. Dynamic Master Curves of Polymer Modified Asphalt from Three Different Geometries. Applied Rheology 2003; 13(3):118124.

40. Dealy JM, Wissbrun KF. Melt rheology and its role in plastics processing. Dordrecht, Netherland: Kluwer Academic Publishers, 1999.

41. Ferry JD. Viscoelastic Properties of Polymers. New York: Wiley, 1980.

42. Song M, Hammiche A, Pollock HM, Hourston DJ, Reading M. Modulated differential scanning calorimetry: 1. A study of the glass transition behavior of blends of poly(methyl methacrylate) and poly(styrene-co-acrylonitrile). Polymer 1995; 36:3313-3316.

43. Song M, Hourston DJ, Schafer FU, Pollock HM, Hammiche A. Modulated differential scanning calorimetry: XVI. Degree of mixing in interpenetrating polymer networks. Thermochim Acta 1998; 315:25-32. 
44. Song M, Hourston DJ. Temperature-modulated differential scanning calorimetry. IX. Some comments on the rigid amorphous fraction in semi-crystalline poly(ethylene terephthalate). $\mathrm{J}$ Thermal Anal 1998; 54:651-657.

45. Wunderlich B. The Nature of the Glass Transition and Its Determination by Thermal Analysis. In Assignment of the Glass Transition; ASTM: Philadelphia, PA, USA, 1994; p 17-31.

46. Wunderlich,B. Reversible Crystallization and the Rigid-Amorphous Phase in Semicrystalline Macromolecules. Progress in Polymer Science 2003; 28(3): 383-450.

47. Struik LCE. The mechanical and physical aging of semicrystalline polymers. Polymer 1987; 28:1521-1533.

48. Struik LCE. Physical Aging in Amorphous Polymers and Other Materials. Elsevier: Amsterdam, The Netherlands, 1978.

49. Polacco G, Berlincioni S, Biondi D, Stastna J, Zanzotto L. Asphalt Modification with Different Polyethylene-based Polymers. Euro Polym Jnl 2005; 41:2831-2844.

50. Polacco G, Stastna J, Vlachovicova Z, Biondi D, Zanzotto L. Temporary Networks in Polymer Modified Asphalts. Polymer Engineering and Science 2004; 44:2185-2193.

51. Kriz P, Stastna J, Zanzotto L. Glass Transition and Phase Stability in Asphalt Binders. International Journal of Road Materials and Pavement Design 2008; 9: 37-65. 


\section{Figure captions}

Figure 1: XRD patterns of: a) BA, b) 20A, c) B1, d) B3, e) B4.

Figure 2: XRD patterns of: a) 20A, b) SBS+ 5wt $\%$ 20A, c) SBS+ $10 w t \% 20 A$, d) SBS $+40 w t \%$ 20A.

Figure 3: XRD patterns of: a) BA, b) BA/SBS, c) 20A, d) BA/20A, e) BA/SBS/20A, f) $\mathrm{BA} / \mathrm{master}$.

Figure 4: Derivative of reversing heat capacity versus temperature signal for samples BA, $\mathrm{BA} / \mathrm{SBS}, \mathrm{B} 1, \mathrm{PM}$ and MB.

Figure 5: DSC thermograms of samples BA, BA/SBS, B1, PM and MB.

Figure 6: Loss tangent, reference temperature: $\operatorname{Tr}=0^{\circ} \mathrm{C}$.

Figure 7: Loss tangent, reference temperature: $\operatorname{Tr}=0^{\circ} \mathrm{C}$.

Figure 8: $\mathrm{T}-\omega_{0}$ map, sample BA $\left(\omega_{0}=0.01 \mathrm{~Hz}\right)$.

Figure 9: $\quad \mathrm{T}-\omega_{0}$ map, sample BA/SBS $\left(\omega_{0}=0.01 \mathrm{~Hz}\right)$.

Figure 10: $\mathrm{T}-\omega_{0}$ map, sample MB $\left(\omega_{0}=0.01 \mathrm{~Hz}\right)$.

Figure 11: T - $\omega_{0}$ map, sample PM $\left(\omega_{0}=0.01 \mathrm{~Hz}\right)$. 


\section{Tables}

\begin{tabular}{|c|c|c|c|c|c|c|}
\hline \multirow{2}{*}{ BA/20A } & \multirow{2}{*}{$\begin{array}{c}\text { 20A } \\
(\%)\end{array}$} & \multicolumn{4}{|c|}{ Softening point $\left({ }^{\circ} \mathbf{C}\right)$} & \multirow{2}{*}{$\begin{array}{c}\text { Penetration } \\
\left(\mathbf{2 5}{ }^{\circ} \mathbf{C}\right)\end{array}$} \\
\cline { 3 - 6 } & & $\begin{array}{c}\text { End of } \\
\text { mixing }\end{array}$ & Top & Bottom & $\Delta \mathbf{~ T}$ & \\
\hline B1 & 2.67 & 46.0 & 44.0 & 46.5 & 2.5 & 95 \\
\hline B2 & 5 & 51.0 & 49.0 & 50.0 & 1.0 & 83 \\
\hline B3 & 7.5 & 64.0 & 75.0 & 72.0 & 3.0 & 48 \\
\hline B4 & 10 & 98.0 & 105.0 & 103.0 & 2.0 & 37 \\
\hline
\end{tabular}

Table $1-\mathrm{BA} / 20 \mathrm{~A}$ blends.

\begin{tabular}{|c|c|c|c|}
\hline sample & $\begin{array}{c}\mathbf{T}_{\mathbf{g}} \text { (DSC) } \\
\left({ }^{\circ} \mathbf{C}\right)\end{array}$ & $\begin{array}{c}\mathbf{T}_{\mathbf{g}} \text { (Rheology) } \\
\left({ }^{\circ} \mathbf{C}\right)\end{array}$ & $\begin{array}{c}\mathbf{T}_{\mathbf{N}} \text { (Rheology) } \\
\left({ }^{\circ} \mathbf{C}\right)\end{array}$ \\
\hline BA & -36.0 & -35.6 & 70.3 \\
\hline BA/SBS & -35.7 & -35.1 & 72.7 \\
\hline B1 & -36.8 & -36.0 & 70.0 \\
\hline PM & -35.1 & -35.8 & 90.6 \\
\hline MB & -35.1 & -35.2 & 70.3 \\
\hline
\end{tabular}

Table 2 - Glass and Newtonian transitions in the blends. 
Figure(s)
Click here to download high resolution image

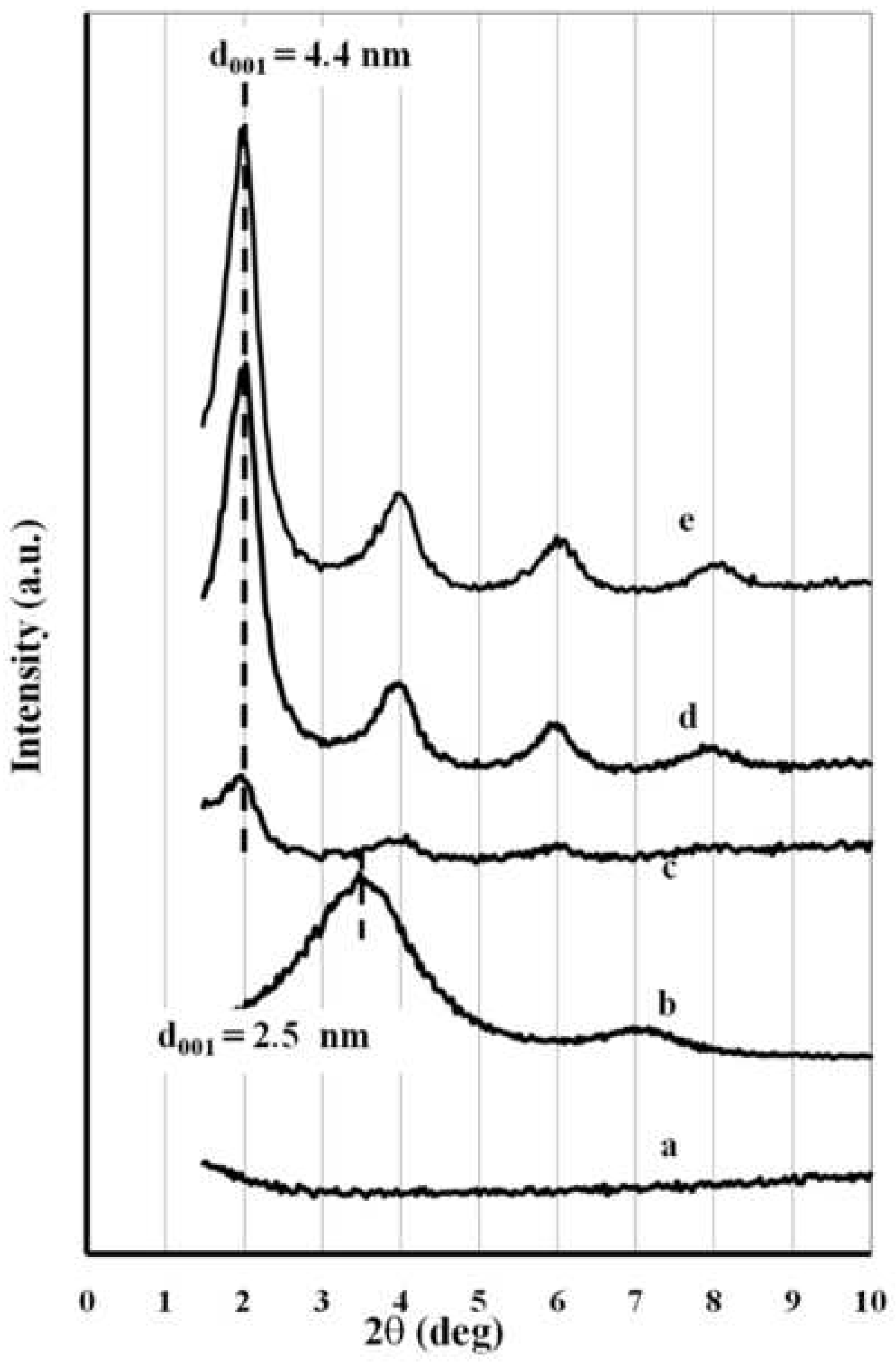


Figure(s)

Click here to download high resolution image

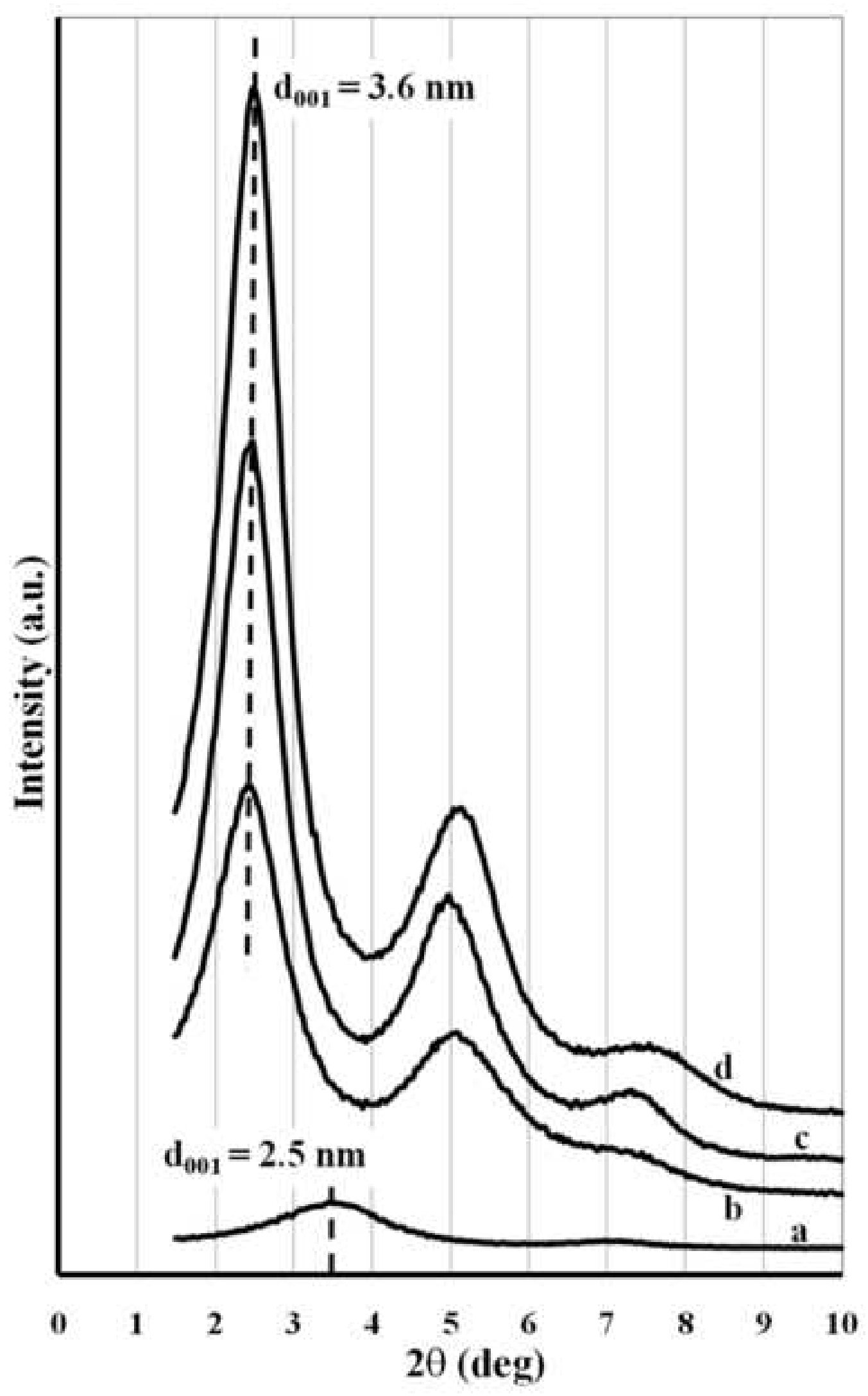


Figure(s)
Click here to download high resolution image

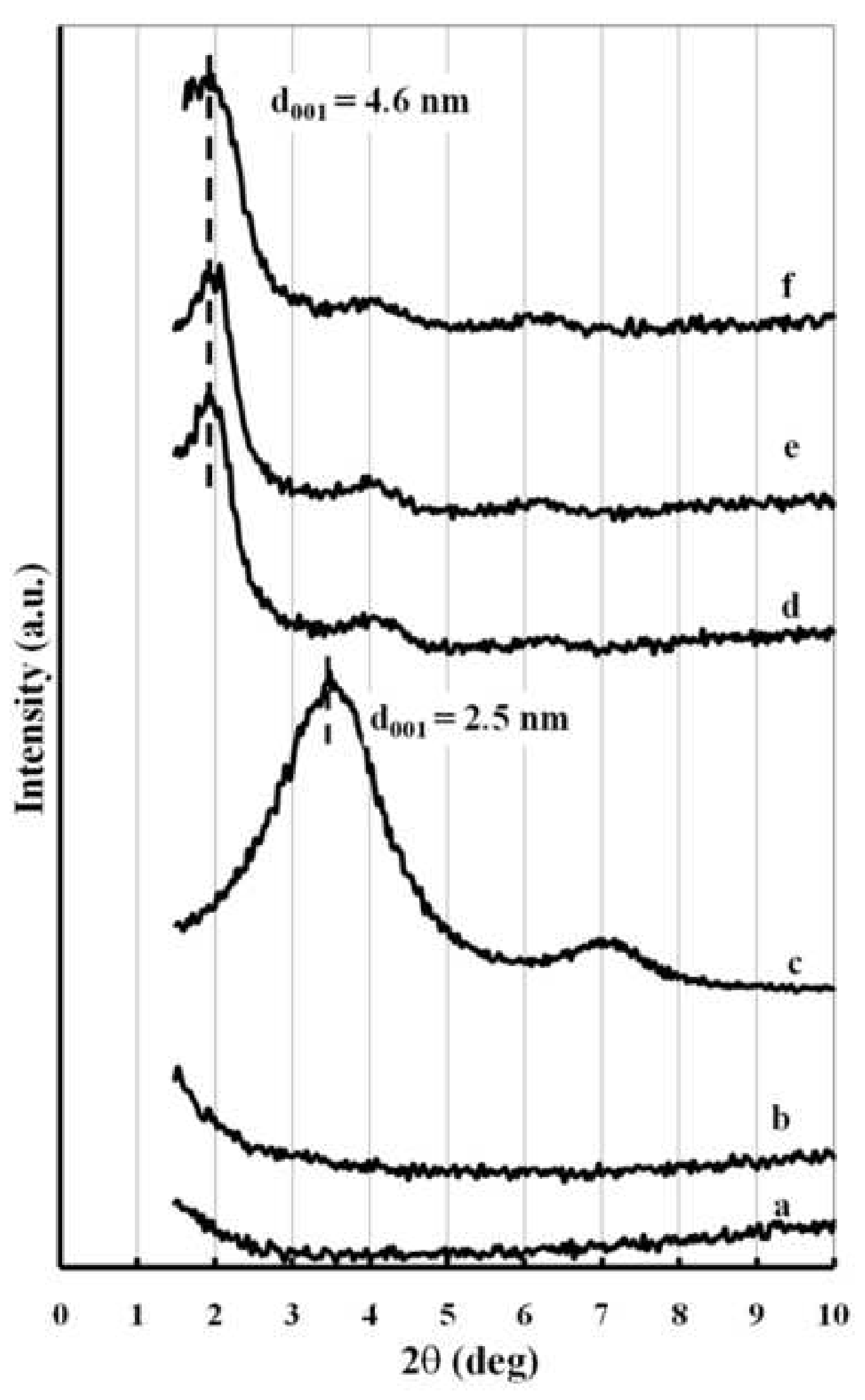




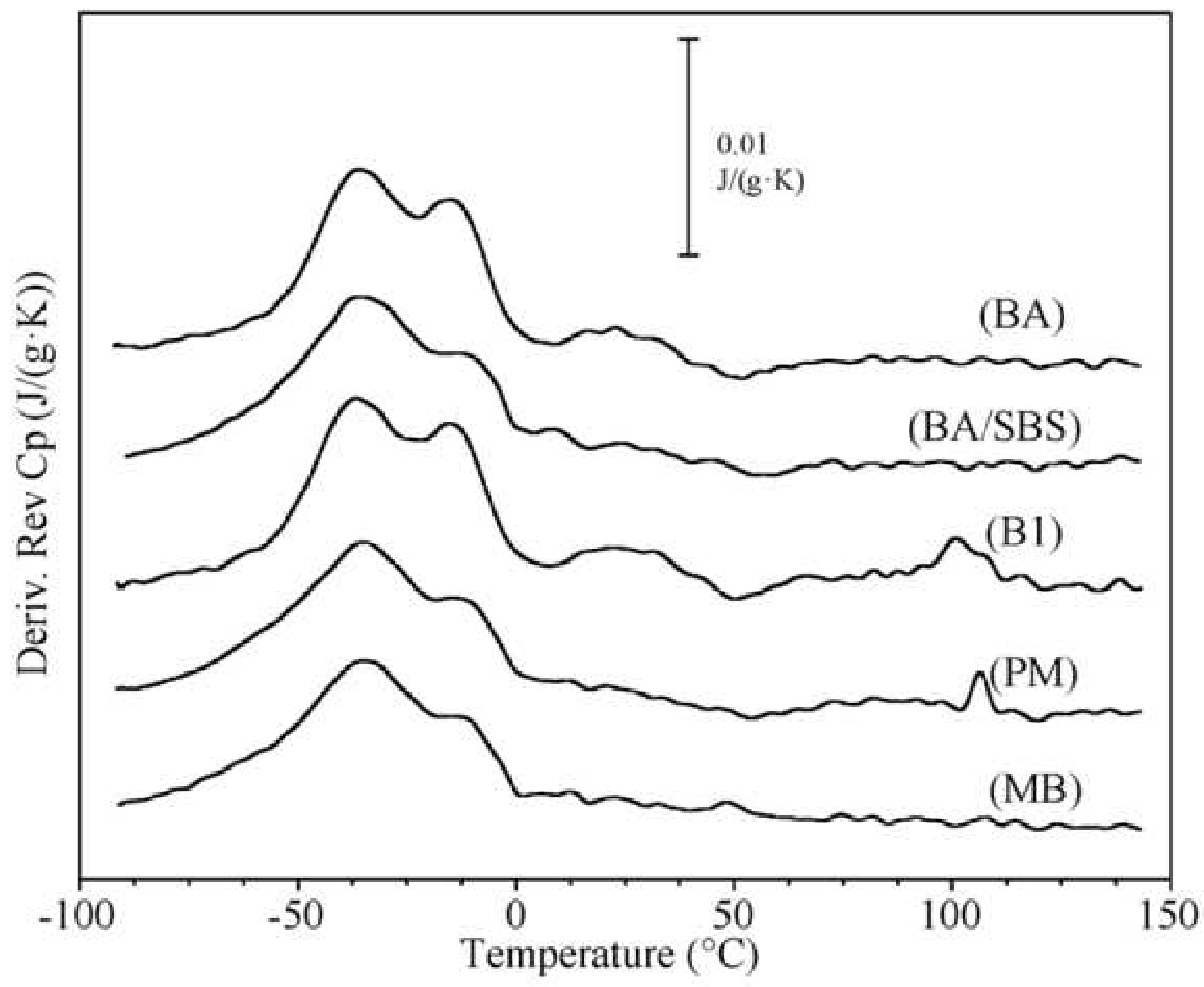




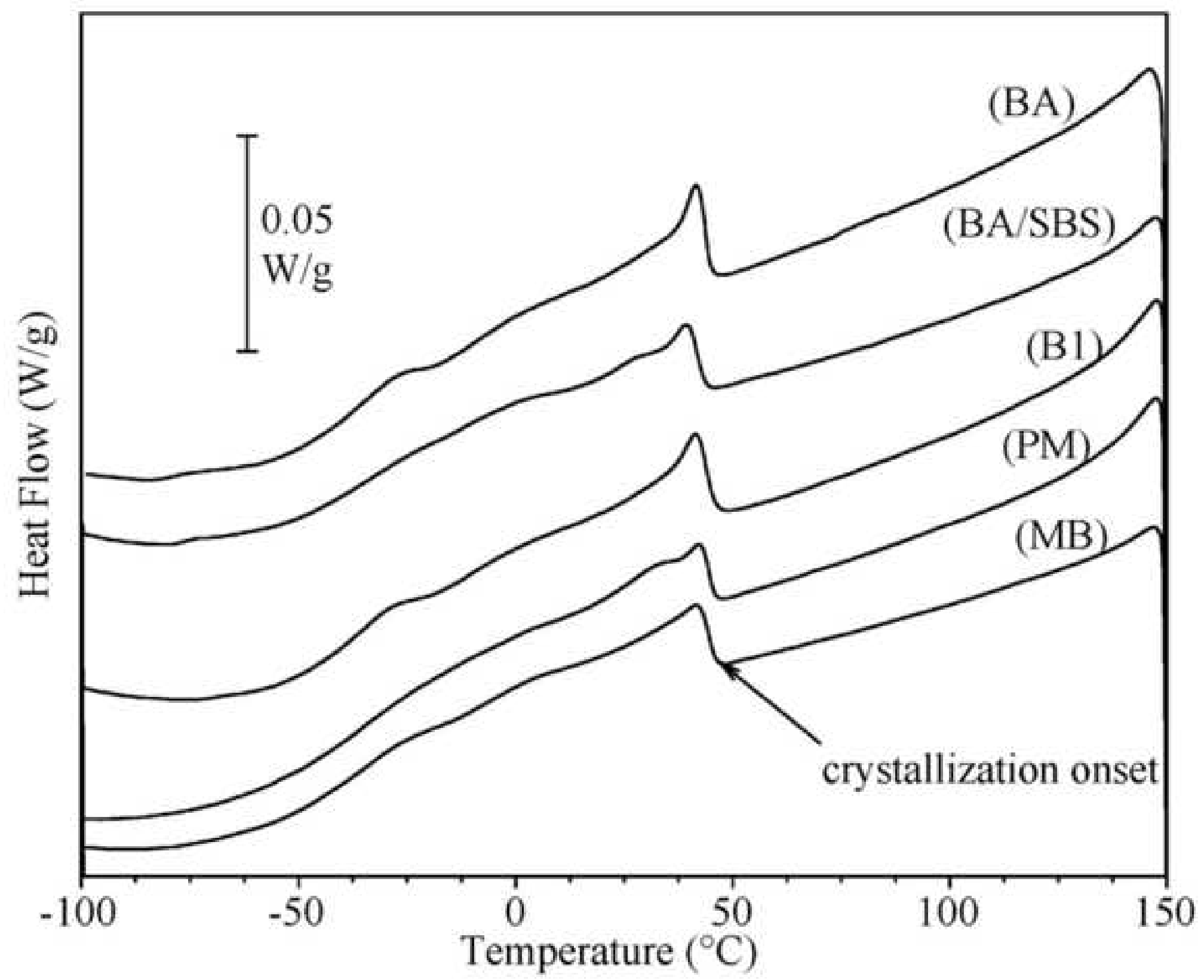




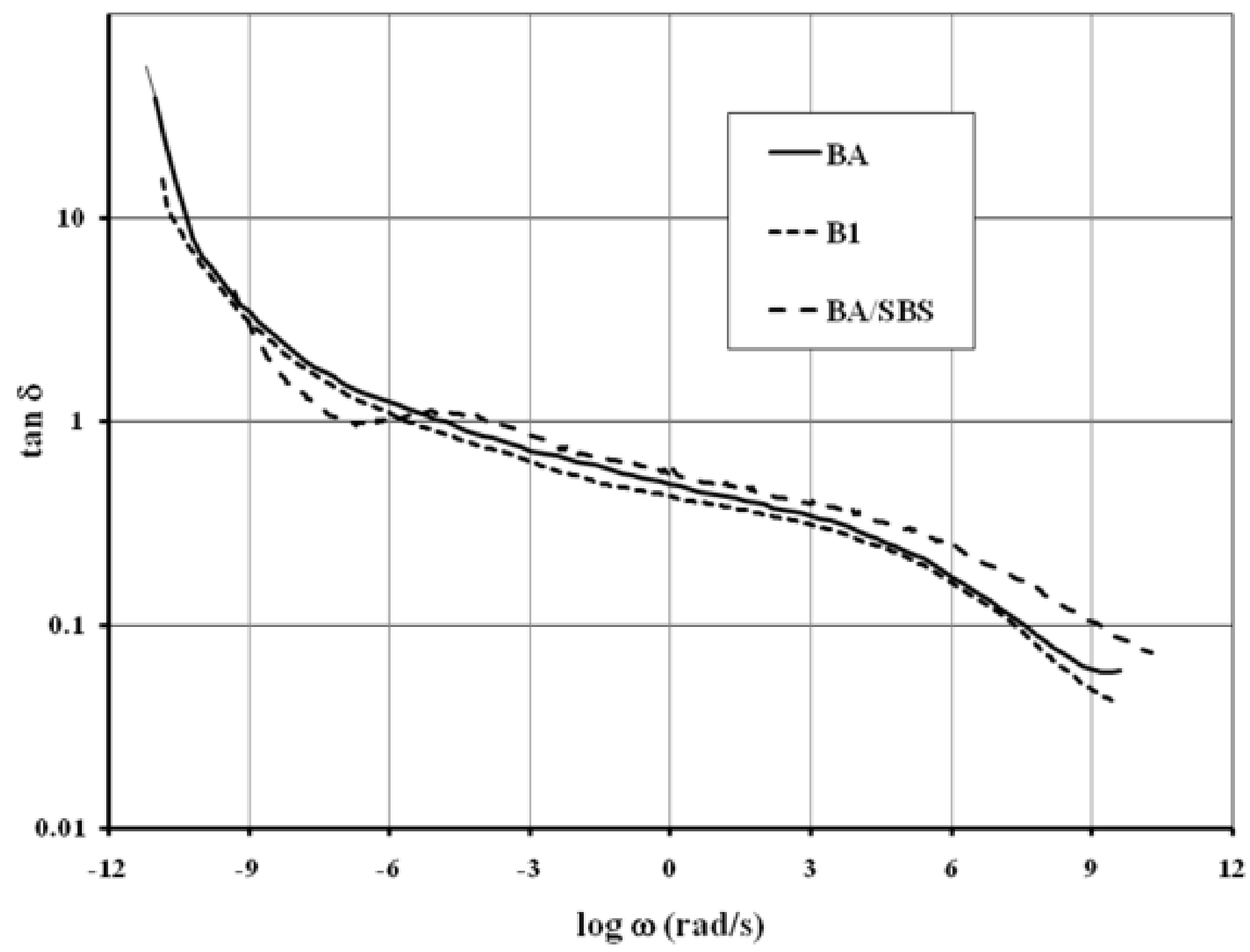




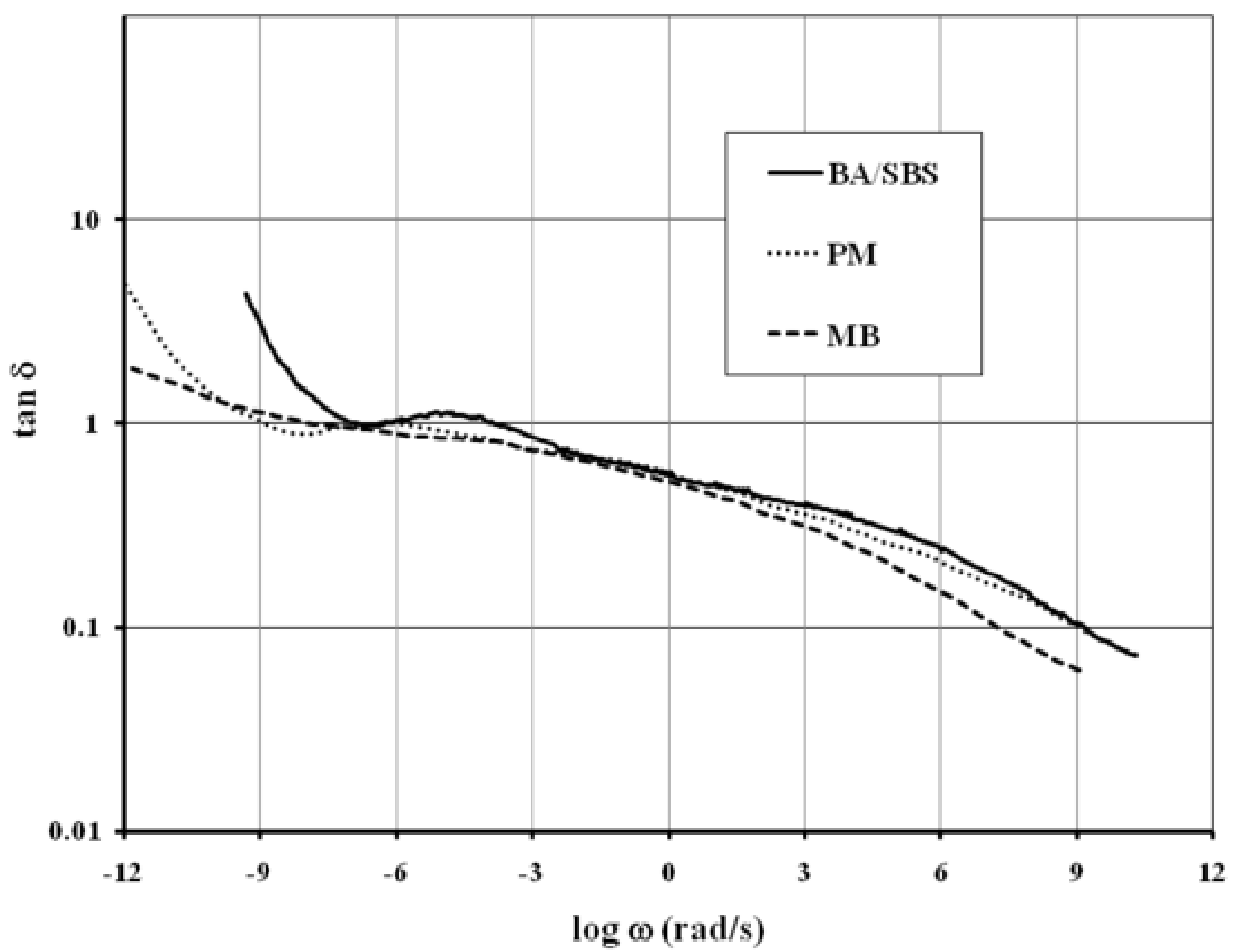


Click here to download high resolution image

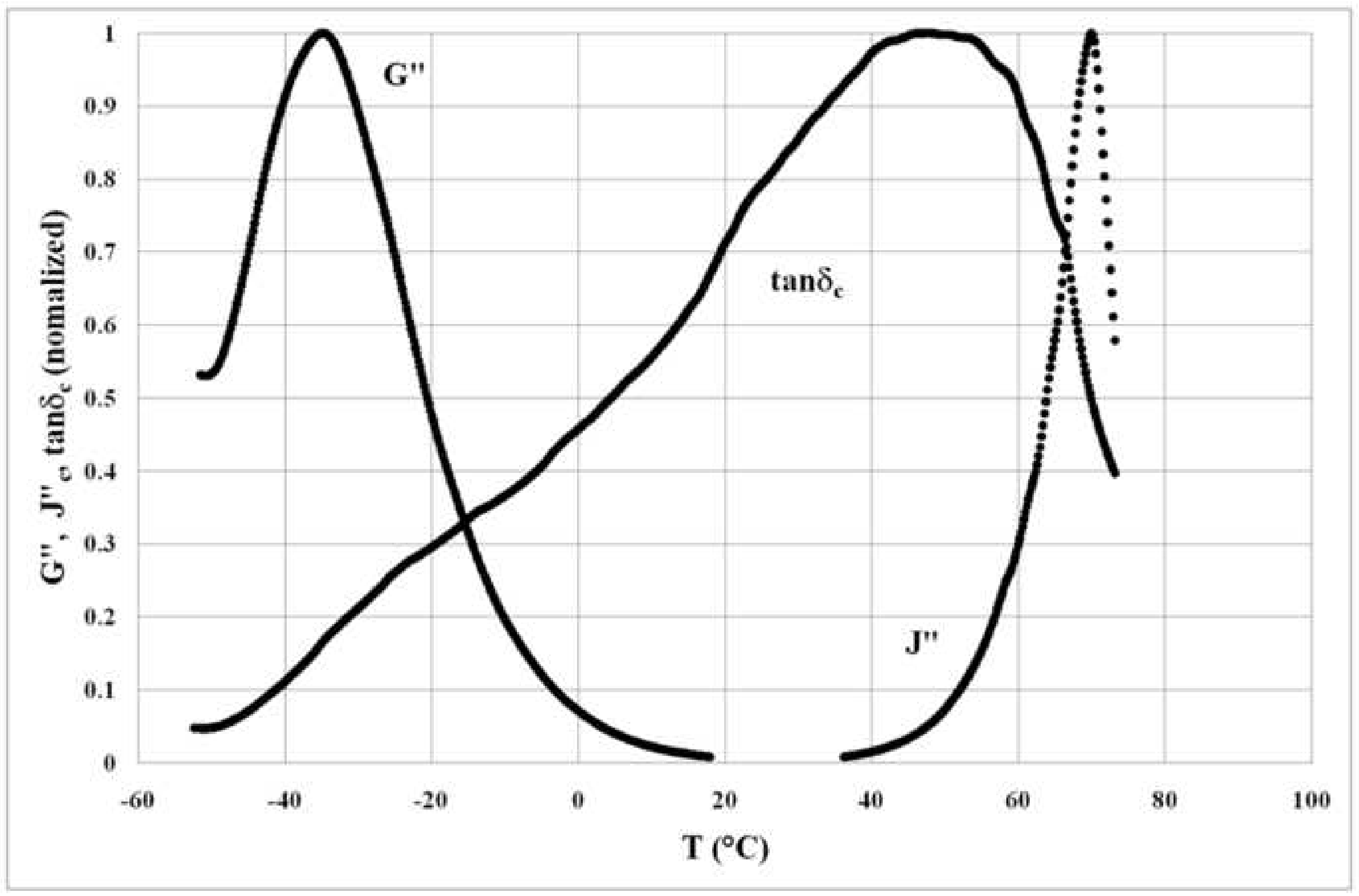


Click here to download high resolution image

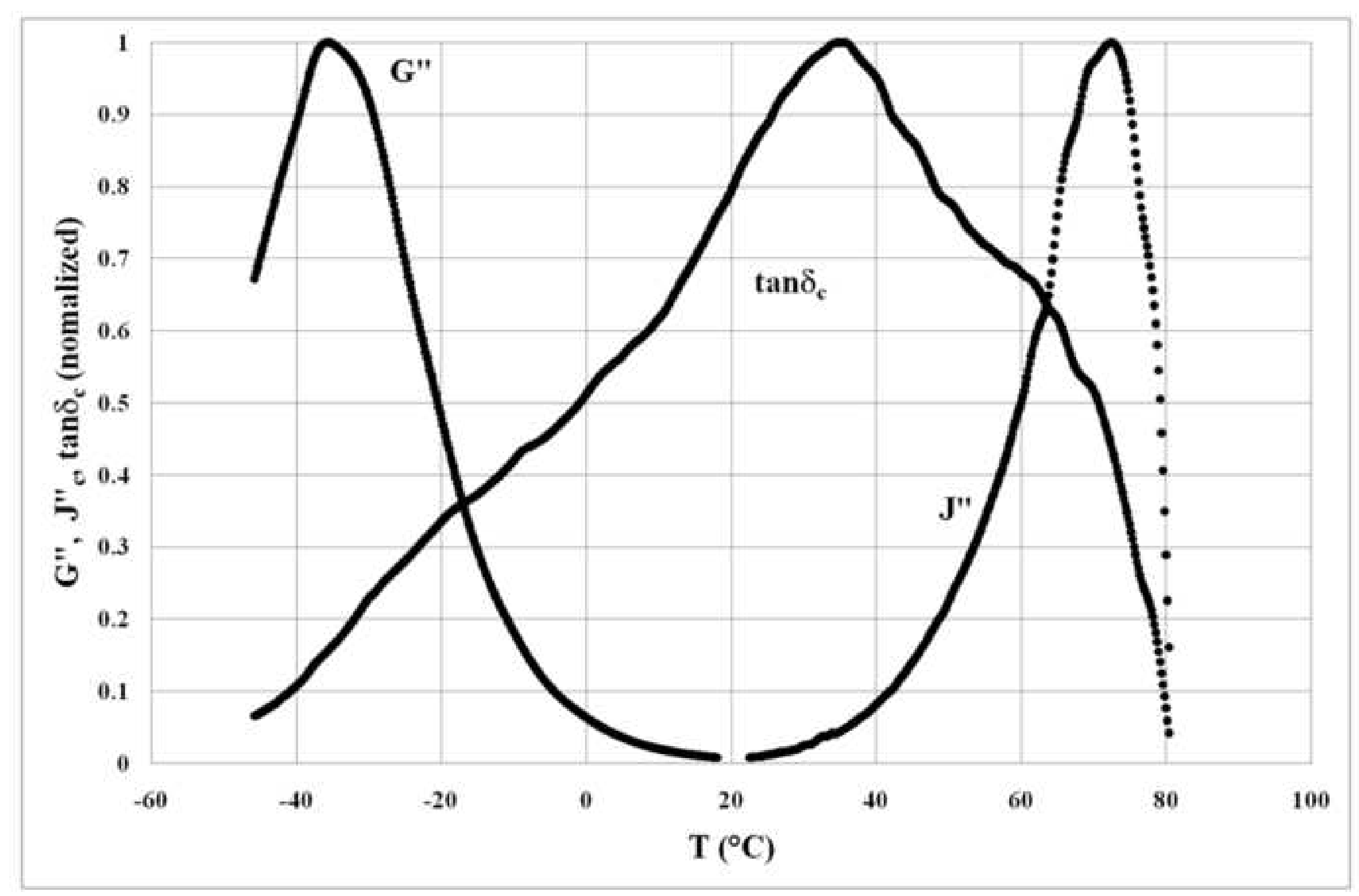


Figure(s)
Click here to download high resolution image

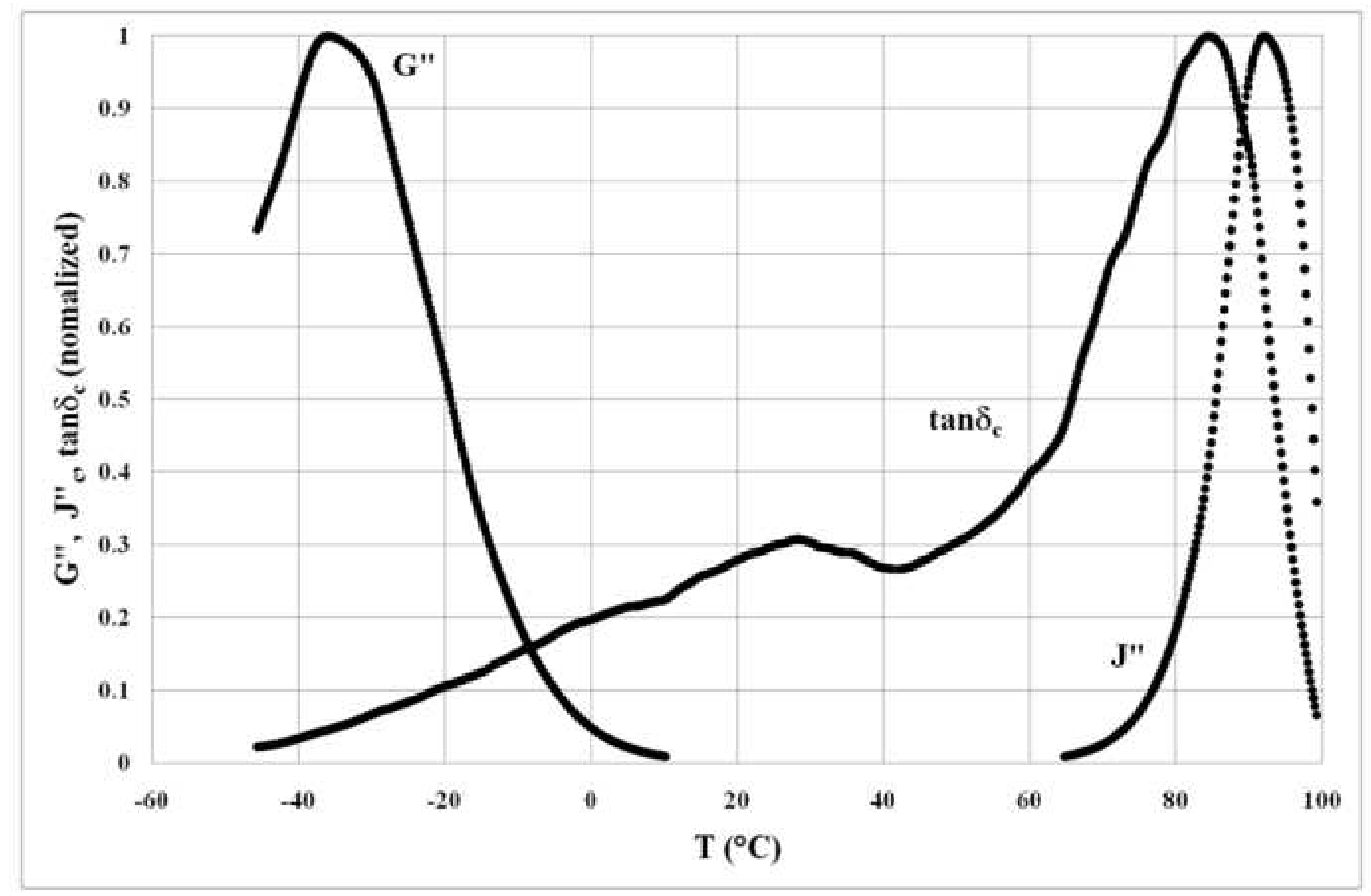




\section{Reviewer \#1:}

Same minor points should be addressed before the publication in the journal: In the section MATERIALS AND METHODS some information are missing: - The temperature of penetration test should be added in the table 1 . The temperature has been added in the Table

- The number of the decimals used in table 1 have to be fixed and coherently used for all the values reported in Table 1 and through the whole text of the manuscript

Done

- Detailed information on the clay sample managing have to be disclaimed (drying procedure, mixing procedures, etc).

This was already presented in the materials and methods section

"The polymer was carefully dried under vacuum at $70^{\circ} \mathrm{C}$, while both the asphalt and the organoclay were used as received from the suppliers.

Three sets of blends were prepared: 1) SBS/20A, 2) BA/20A and 3) BA/SBS/20A. The SBS/20A blends were prepared by melt compounding in a Brabender Plasticorder static mixer of $50 \mathrm{~mL}$ capacity, preheated to $190^{\circ} \mathrm{C}$. The rotor speed was maintained at $30 \mathrm{rpm}$ for about 2.5 minutes and then it was increased gradually (in 30 second increments) to $60 \mathrm{rpm}$. The organoclay was added into the molten polymer matrix before increasing the rotor speed. The overall blending time was 13 minutes."

- The sentence "...showing the softening point of the top section higher than that of the bottom one..." ( page 7) cannot be take in account as a general comment and should be observed that usually does it happen the contrary.

Usually during storage at high temperature the polymer migrates toward the higher part of the tube, thus determining a very high polymer concentration in the top section. This causes a softening point to be higher than that of the bottom part and it is a "classic" and common effect of phase separation. Probably the referee misunderstood the sentence and thought that it meant the contrary.

\section{Section RESULTS:}

- Page 10: The addition of $2.67 \%$ of $20 \mathrm{~A}$ to the asphalt causes the reduction of penetration to one half of original value. This result cannot be considered very small as claimed by the Authors. 
The sentence:

"The effect of clay content on the softening point and penetration was not linear; it was very small for the lower clay loads and became important only for the B3 and B4 compositions."

has been changed to:

"The effect of clay content on the softening point and penetration was not linear: the variation of softening point was very small for the lower clay loads and became important only for the B3 and B4 compositions, while the penetration was reduced to about one half of the initial value in the B1 and B2 compositions and further halved for B3 and B4."

- $\quad$ Page 11: A table reporting the values of specific densities of the various samples examinated could be of help in the interpretation of results and should be shown.

The specific densities of asphalt and clay have been added in the text.

- $\quad$ Page 15: The frequency of testing $(<$ omega $>0=2<$ pi $>.0 .01)$ should be expressed in $\mathrm{rad} / \mathrm{s}$ or in $\mathrm{Hz}$.

The frequency is indicated as $0.01 \mathrm{~Hz}$

- $\quad$ Figure 2: The graphic representation of value of interlayer spacing is not readable.

Figures 1-3 have been changed

- All Figures should be edited again choosing the same type of font.

All figures have now the same type of font

Reviewer \#2: This paper deals with the use of SBS/clay nanocomposites in the bitumen modification. It is a rather new and interesting way of modification and the article presents different rheological and microstructural techniques for the bitumen characterization. As result, this work deserves publication. However, some major points need to be addressed:

1. The evaluations of the rheological properties and bitumen modification have been carried out on the basis that these polymer modified bitumens are thermorheological simple materials (i.e. they hold the time-temperature superposition). However, this assumption is quite controversial in polymer modified bitumens and, therefore, some evidences should be presented: A) a plot of the raw rheological data, $G^{\prime}$ and $G^{\prime \prime}$ versus frequency in the whole temperature range for some polymer modified bitumens; B) a Black diagram $\left(G^{*}\right.$ vs. phase 
angle) of the polymer modified bitumens; and C) A plot with the experimental shift factors and the WLF fittings.

Of course we are aware of the importance of the thermorheological simplicity and the question of its validity in PMAs raised by some authors. Nevertheless, in our case we observed that the materials behave in a way that can be considered "rheologically simple" and we did not discussed it in the text because we thought that figures 5-10 already show this point. In fact the construction of a master curve is possible only when the time-temperature principle can be applied. In order not to present too many pictures we suggest not to add other figures to the paper, but here you can find the requested graphs. They are built from the raw data and no "editing" has been applied to them.

In the text we added the following sentence:

"In fact this was possible because all the analyzed materials showed to be thermorheologically simple thus making it possible to apply the time-temperature superposition principle."

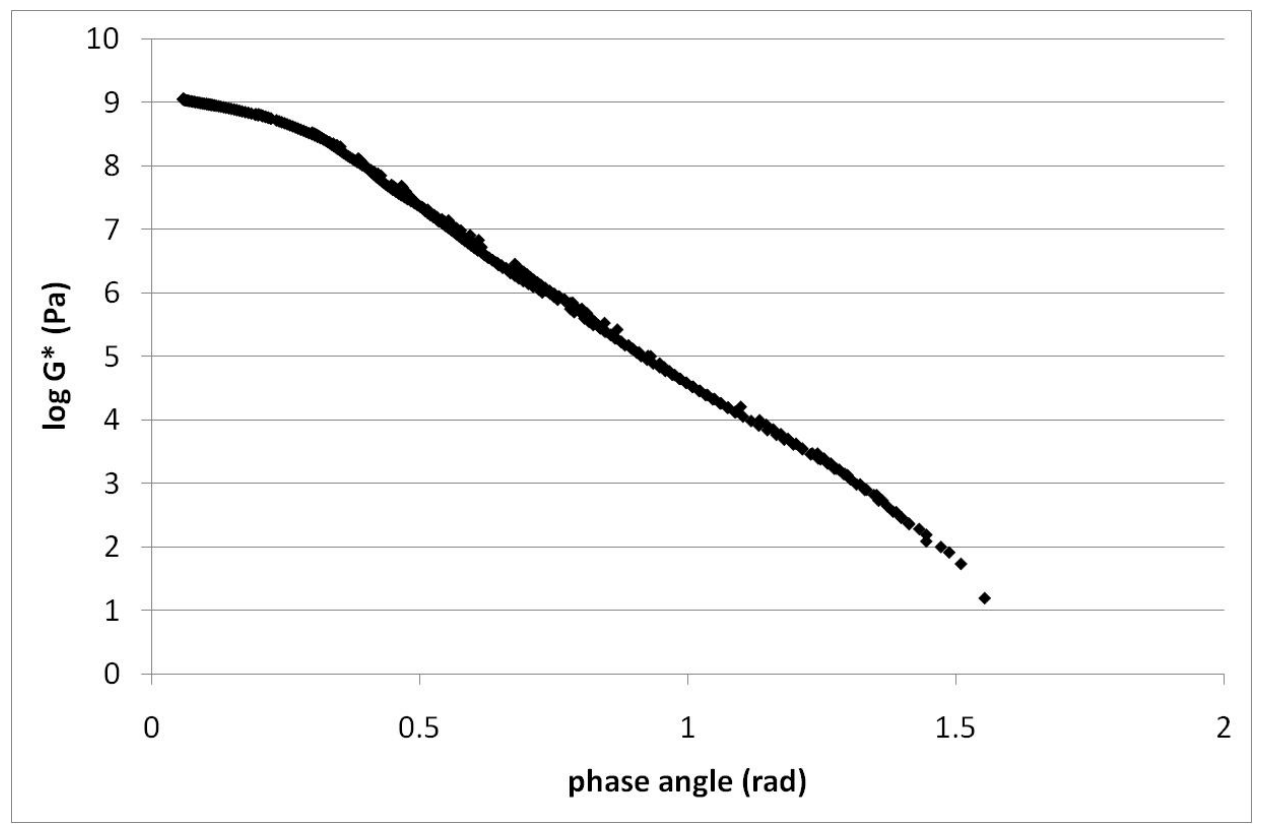

BA black diagram. 


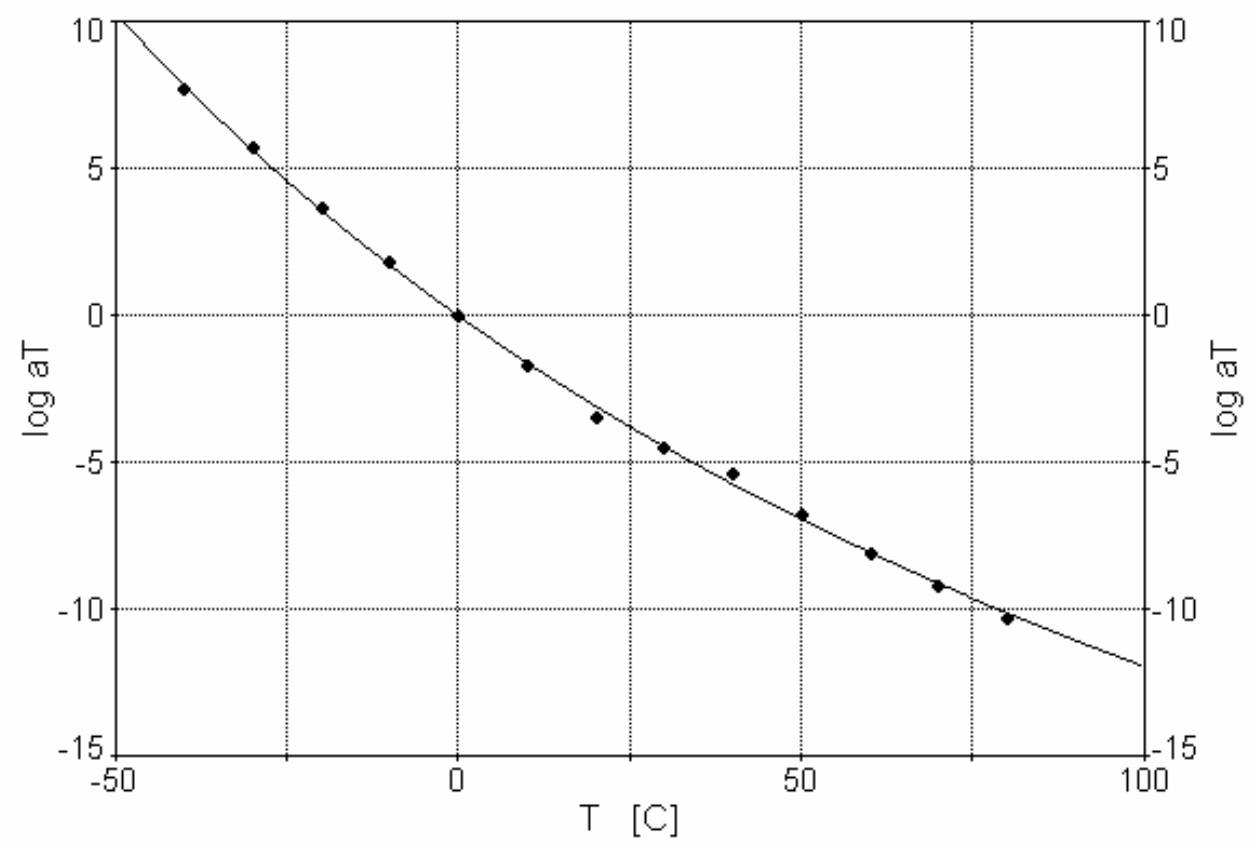

BA horizontal shift factors and WLF fit.

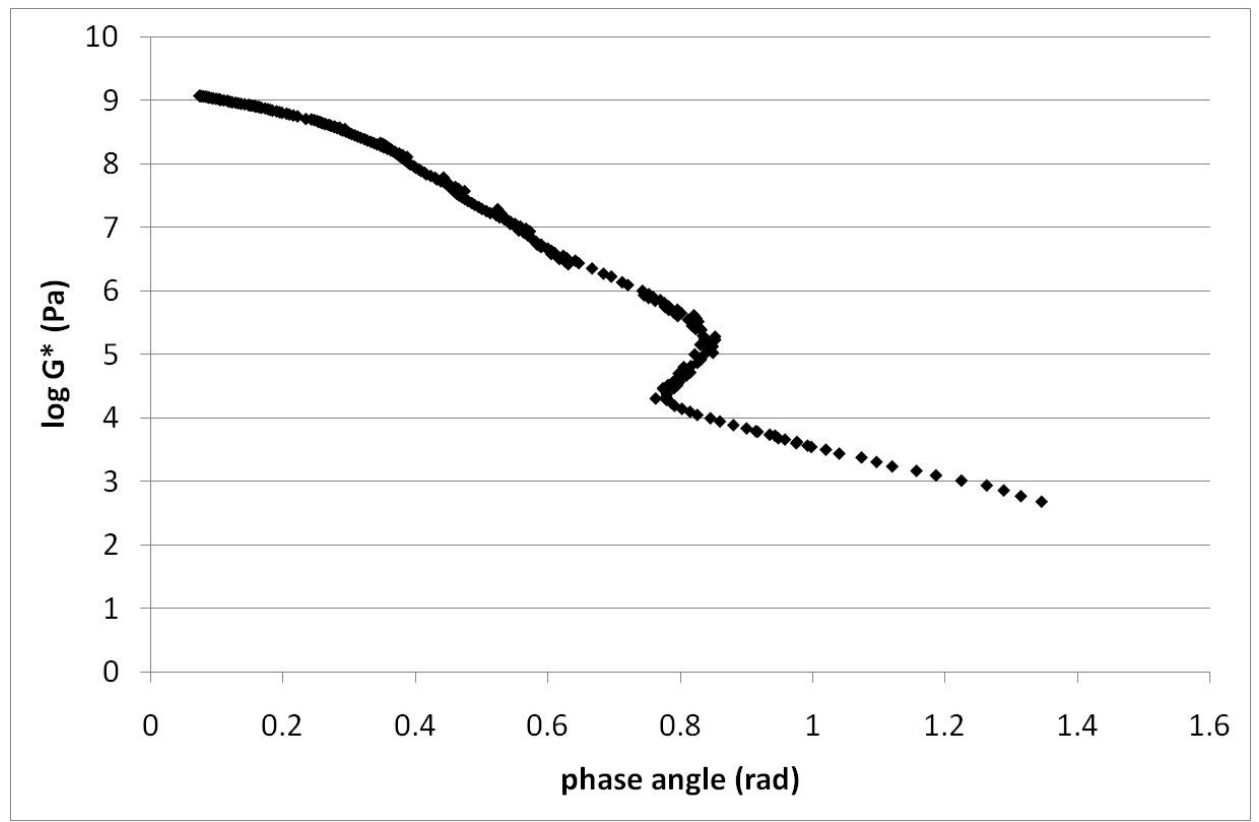

BA/SBS black diagram. 


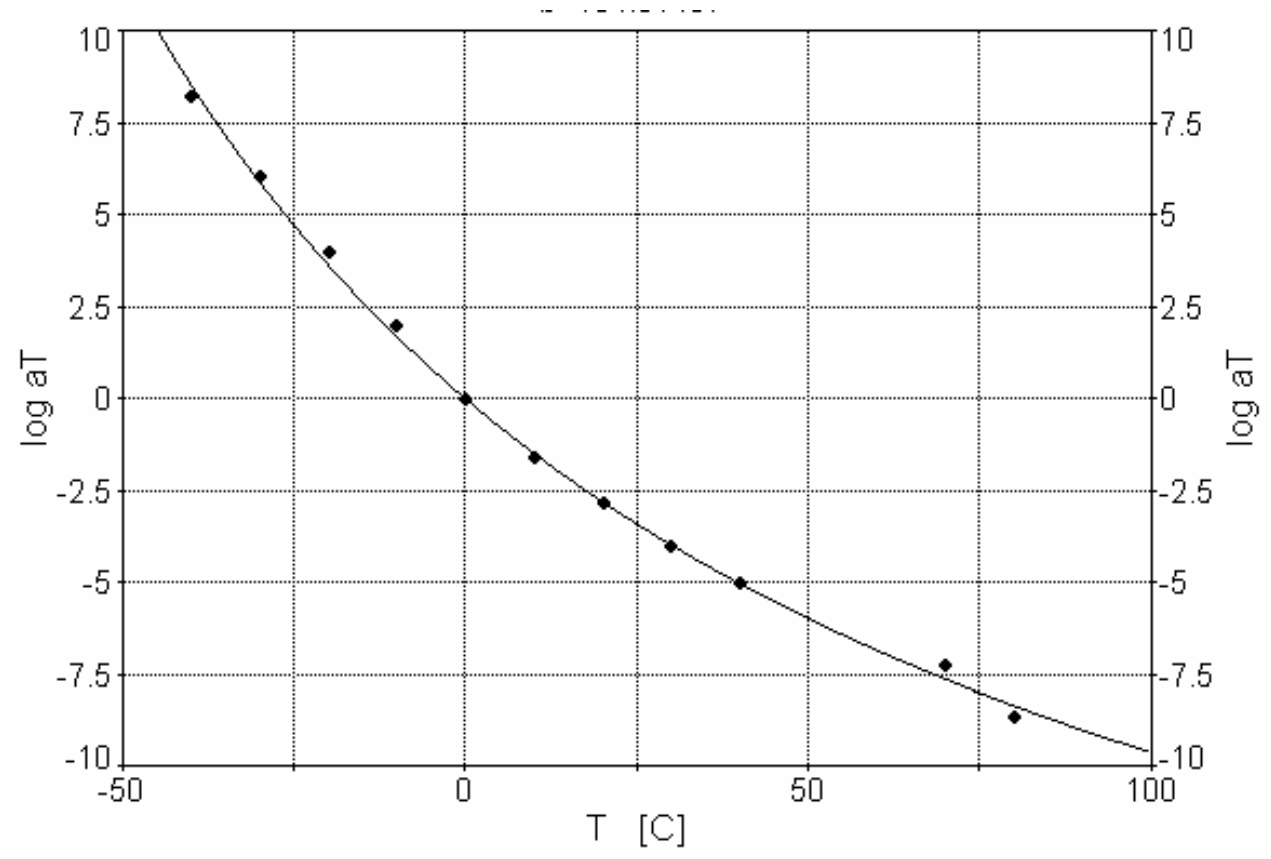

BA/SBS horizontal shift factors and WLF fit.

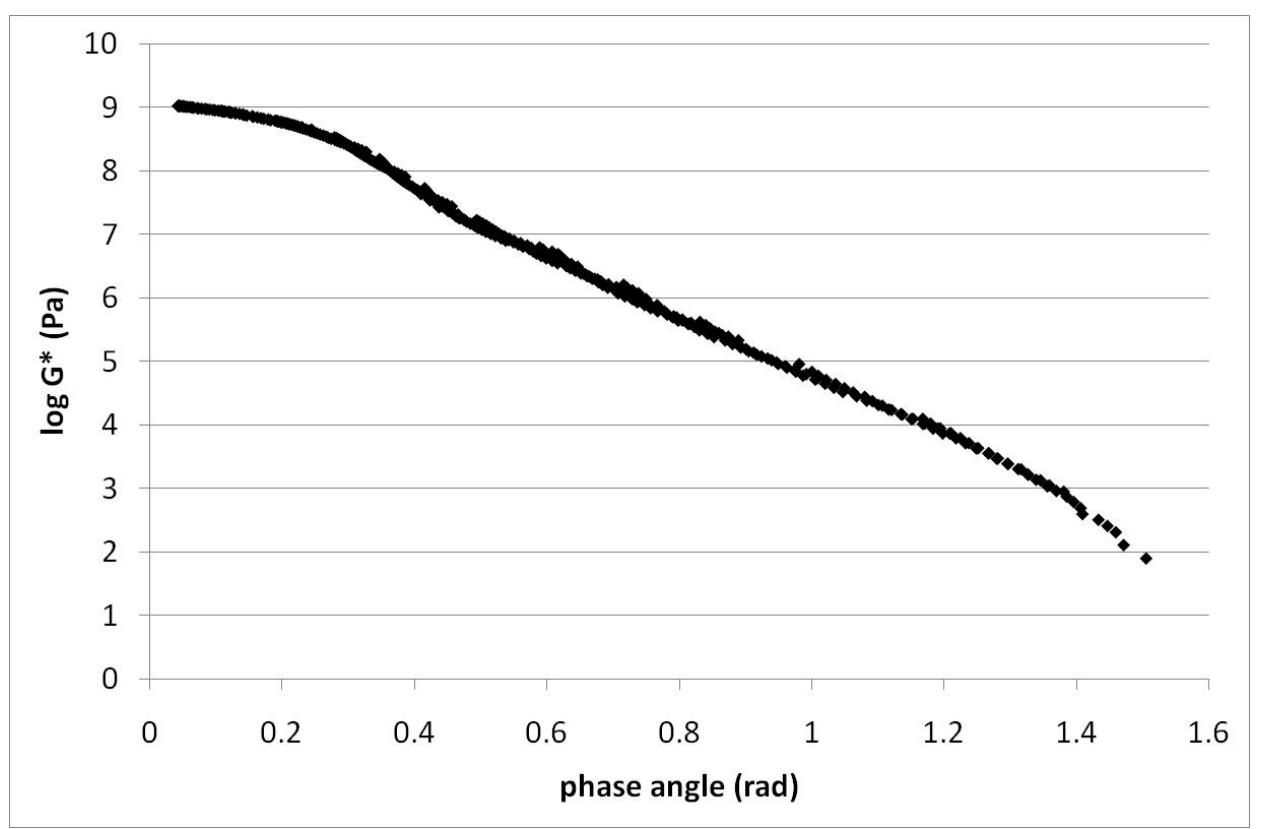

B1 black diagram. 


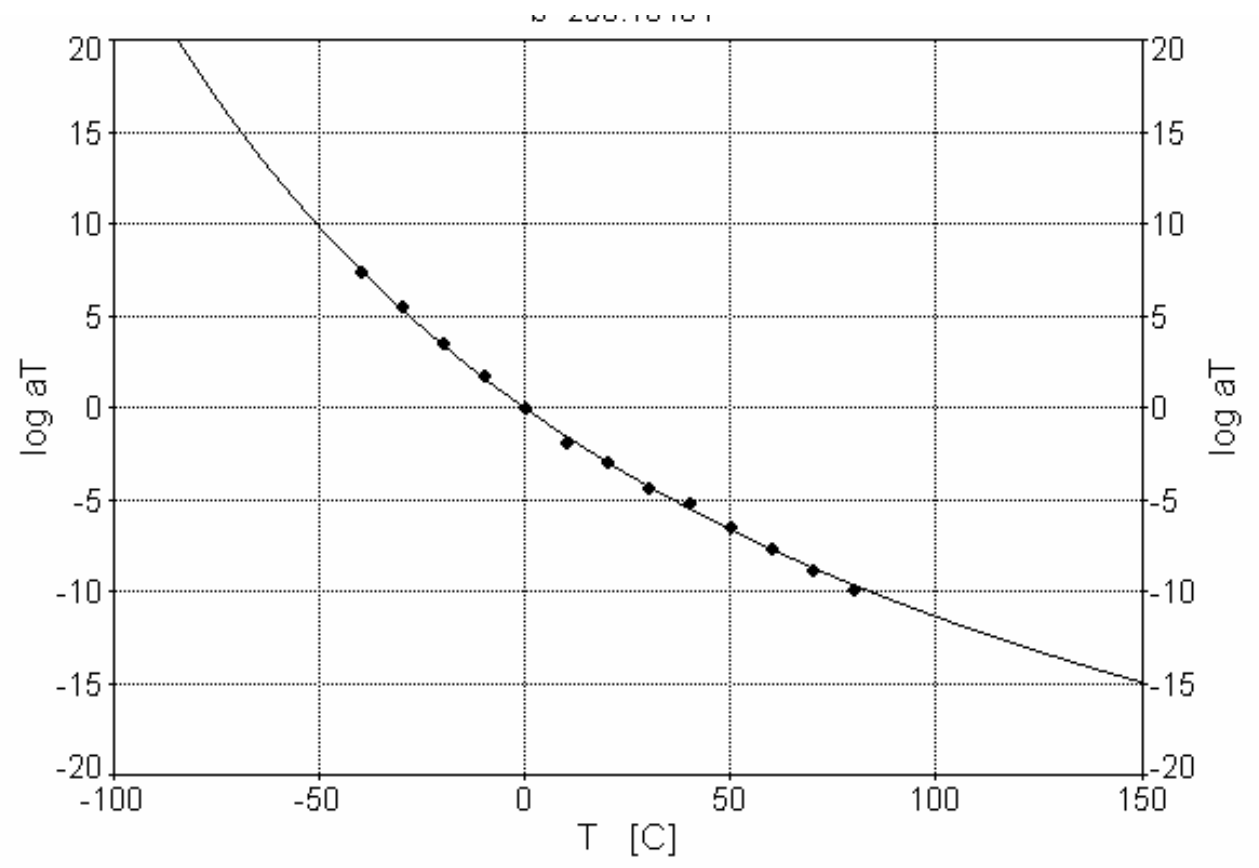

B1 shift factors and WLF fit.

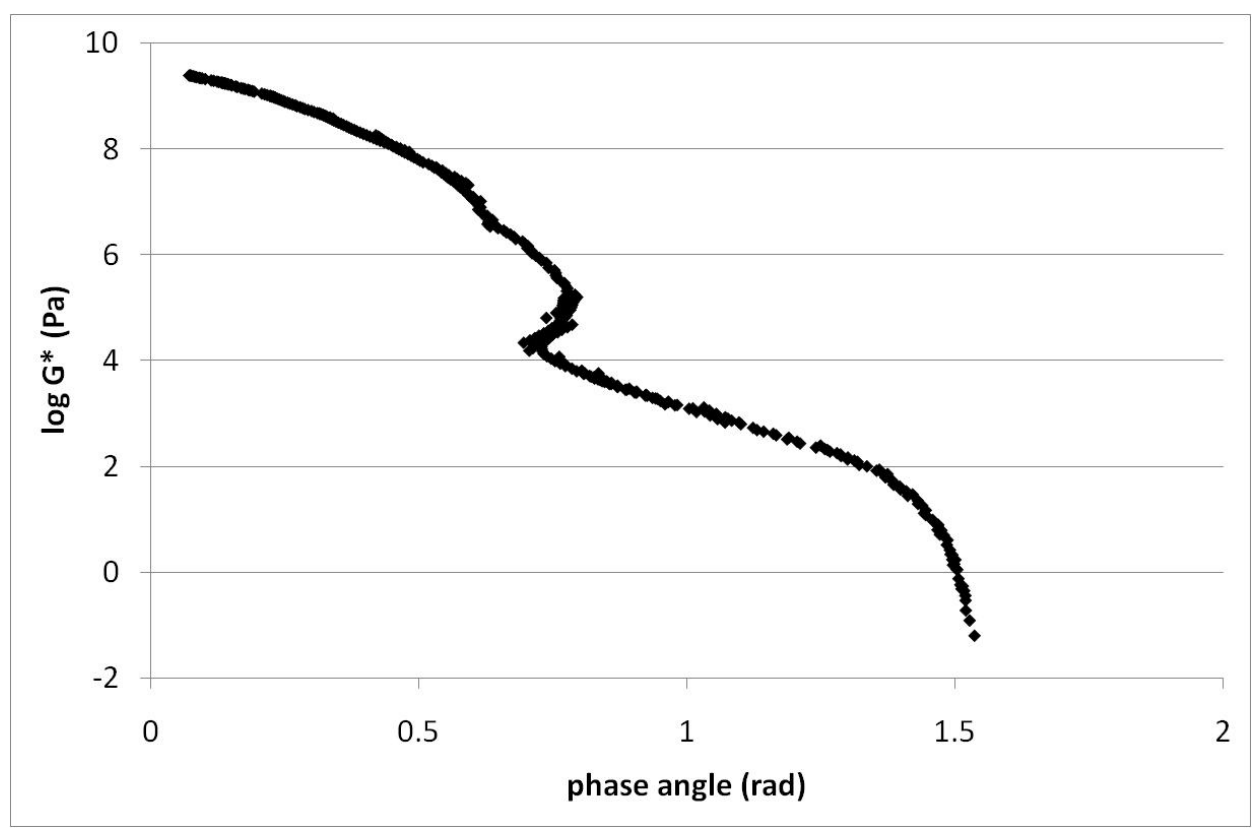

MB black diagram. 


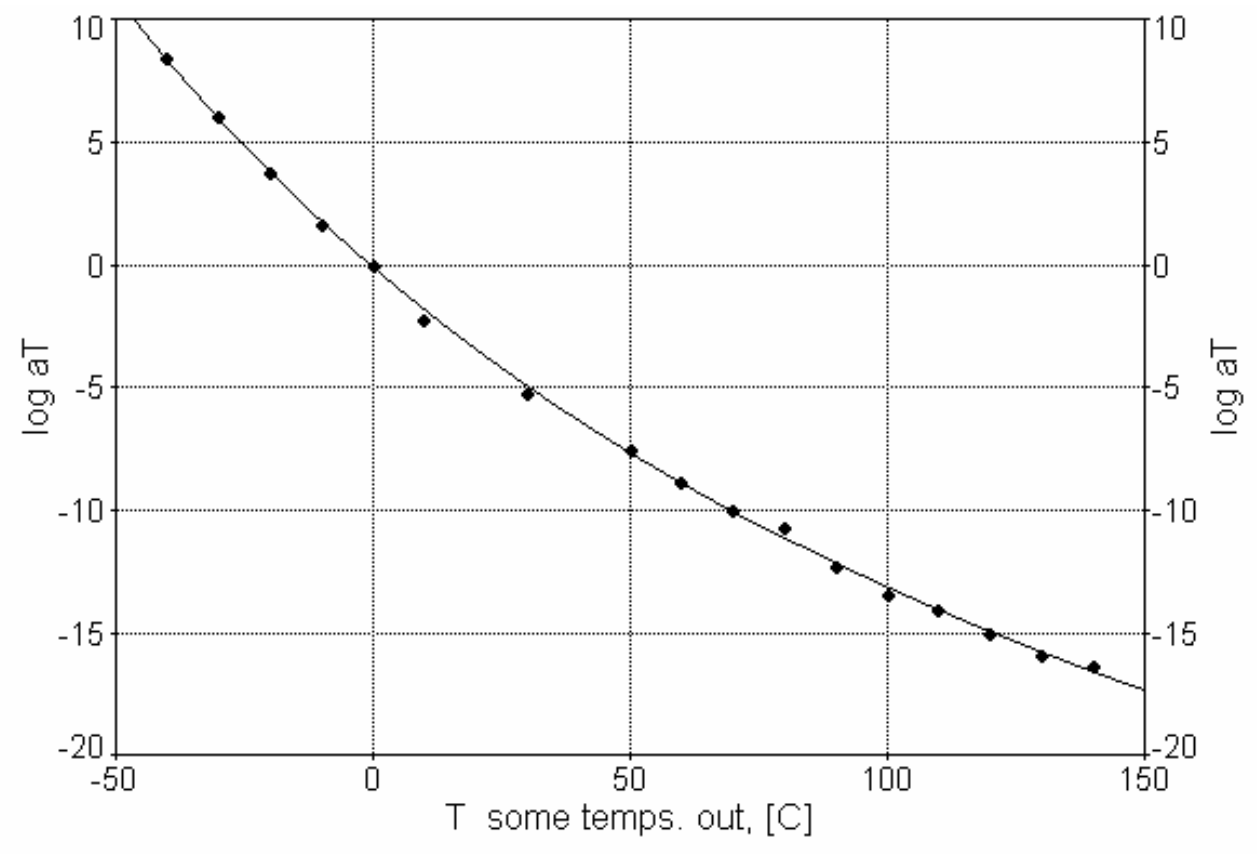

MB horizontal shift factors and WLF fit.

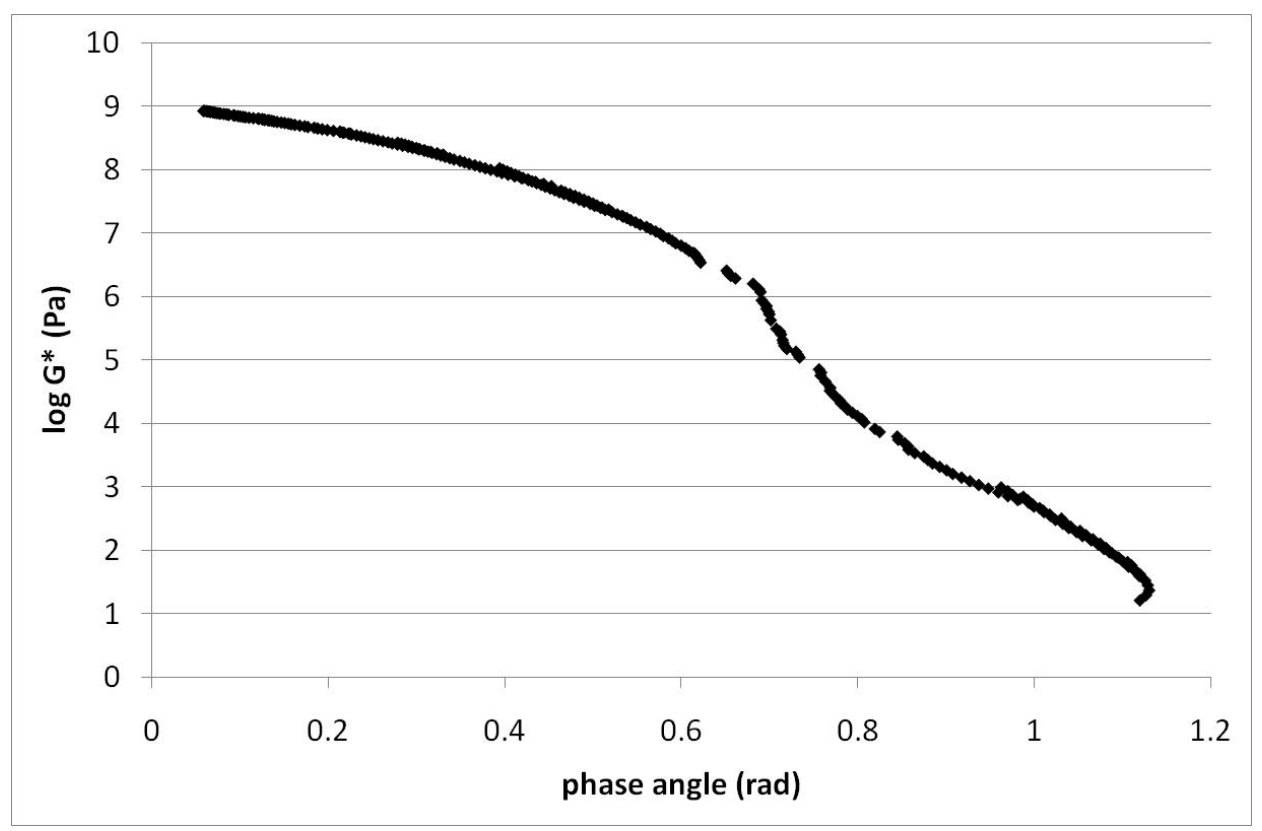

PM black diagram. 


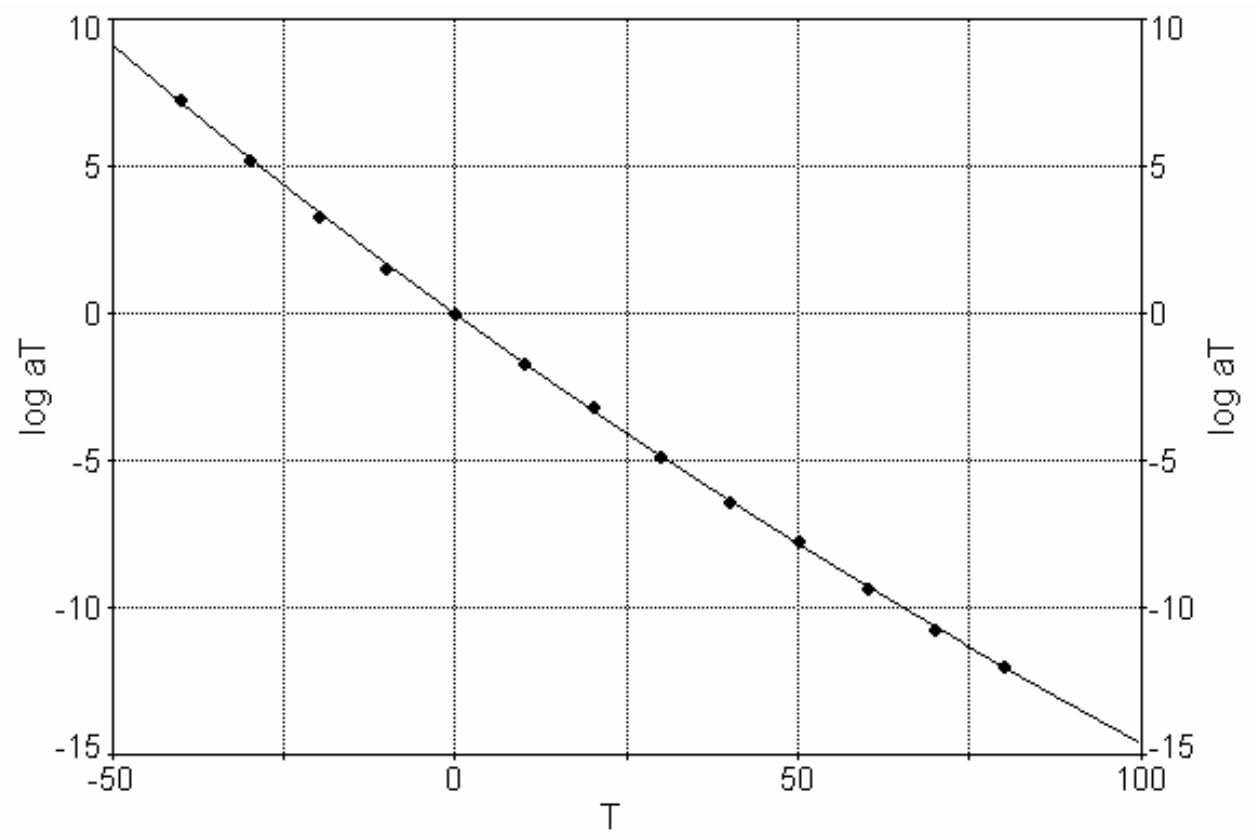

PM horizontal shift factors and WLF fit.

Other minor points:

2. Authors seem to perform the rheological characterization by using two geometries: cone and plate and torsion. The reason for this fact and their temperature range of application would be of great interest for the reader.

The sentence:

"The reason why different geometries were used is the wide range of temperatures covered, thus changing the consistency of the sample from that of a soft viscoelastic solid (when a plate-plate can be used) to a brittle glassy material (when the torsion bar is necessary). The advantages and problems associated with such testing are fully discussed in a previous paper [39]."

has been added - in the Materials and methods section.

The sentence:

"With regard to the sample geometries, for BA, B1 and BA/SBS, $25 \mathrm{~mm}$ diameter parallel plates were used at $\mathrm{T}>20{ }^{\circ} \mathrm{C}, 10 \mathrm{~mm}$ parallel plates at $\mathrm{T}=10-30{ }^{\circ} \mathrm{C}$ and rectangular torsional bars $(25.5 \times 12 \times 2.65 \mathrm{~mm})$ at $\mathrm{T}$ lower than $20^{\circ} \mathrm{C}$. For $\mathrm{MB}$ and PM samples the $25 \mathrm{~mm}$ diameter parallel plates were used at $\left.\mathrm{T}>30^{\circ} \mathrm{C}\right), 10 \mathrm{~mm}$ parallel plates at $\mathrm{T}=10-30{ }^{\circ} \mathrm{C}, 50 \mathrm{~mm}$ parallel plates at $\mathrm{T}>100^{\circ} \mathrm{C}$ and rectangular torsional bars $(25.5 \times 12 \times 2.65 \mathrm{~mm})$ at $\mathrm{T}<20^{\circ} \mathrm{C}$."

has been added - in the Result and discussion section. 
3. Authors discuss about MDSC and standard DSC measurements. However, the latter are no presented and, it is likely, they are necessary to understand bitumen crystallinity. In the same way, please describe the thermal events related to such crystallinity on the plot.

The DSC measurements have been added (Figure 5).

4. Regarding the good agreement between rheological and MDSC Tgs (table 2), authors should clarify that the rheological $\mathrm{Tg}$ depends on the selected frequency (in this case $0.01 \mathrm{~Hz}$ ).

The sentence:

"After the transformation of the frequency domain to the temperature domain (with the testing frequency $\omega_{0}=0.01 \mathrm{~Hz}$ ), one can see that samples BA and B1 again exhibited very similar behaviour (BA is reported in Figure 7); and, the estimated glass transition temperatures (the position of maximum of $\left.G^{\prime \prime}\left(T, \omega_{0}\right)\right)$, in both cases, were in agreement with the DSC values (Table 2)."

has been changed in:

"After the transformation of the frequency domain to the temperature domain (with the testing frequency $\omega_{0}=0.01 \mathrm{~Hz}$ ), one can see that samples BA and B1 again exhibited very similar behaviour (BA is reported in Figure 8). Moreover, at the chosen frequency [51] the estimated glass transition temperatures (the position of maximum of $G$ ' $\left.\left(T, \omega_{0}\right)\right)$, in both cases, were in agreement with the DSC values (Table 2)."

Reference 51 was added.

5. Introduction needs to be largely reduced and some references should be included in page 2 paragraphs 1 and 2 and page 3 paragraphs 3 and 4 .

The introduction has been reduced from 2,260 to 1,357 words.

References 1,2 14-17 have been added. 